WSRC-TR-2003-00144, Rev. 0

Keywords: Waste processing, actinides, F Canyon

Retention: Permanent

\title{
RESULTS OF NEPTUNIUM DISPOSAL TESTING
}

D. D. Walker

M. R. Poirier

T. L. Fellinger

E. K. Hansen

May 22, 2003

Westinghouse Savannah River Company

Savannah River Technology Center

Aiken, SC 29808

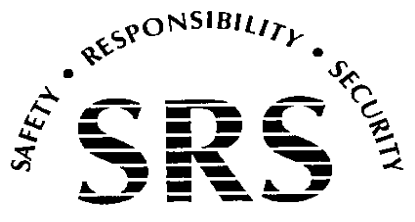


This document was prepared in conjunction with work accomplished under Contract No. DE-AC09-96SR18500 with the U. S. Department of Energy.

\section{DISCLAIMER}

This report was prepared as an account of work sponsored by an agency of the United States Government. Neither the United States Government nor any agency thereof, nor any of their employees, makes any warranty, express or implied, or assumes any legal liability or responsibility for the accuracy, completeness, or usefulness of any information, apparatus, product or process disclosed, or represents that its use would not infringe privately owned rights. Reference herein to any specific commercial product, process or service by trade name, trademark, manufacturer, or otherwise does not necessarily constitute or imply its endorsement, recommendation, or favoring by the United States Government or any agency thereof. The views and opinions of authors expressed herein do not necessarily state or reflect those of the United States Government or any agency thereof.

This report has been reproduced directly from the best available copy.

Available for sale to the public, in paper, from: U.S. Department of Commerce, National Technical Information Service, 5285 Port Royal Road, Springfield, VA 22161, phone: (800) 553-6847, fax: (703) 605-6900

email: orders@ntis.fedworld.gov

online ordering: http://www.ntis.gov/help/index.asp

Available electronically at http://www.osti.gov/bridge

Available for a processing fee to U.S. Department of Energy and its contractors, in paper, from: U.S. Department of Energy, Office of Scientific and Technical Information, P.O. Box 62, Oak Ridge, TN 37831-0062,

phone: (865)576-8401,

fax: (865)576-5728

email: $\underline{\text { reports@ adonis.osti.gov }}$ 


\section{CONTENTS}

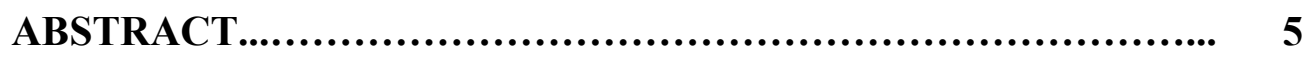

INTRODUCTION............................................... 7

RESULTS and DISCUSSION..................................................... 8

Characterization of Neptunium Solution....................... 8

Neutralization of Neptunium Solution........................ 9

Rheological Testing of Neutralized Solution............................... 14

Mixing and Transfer Modeling...................................................... 19

Hydrogen Generation in Washed Sludge................................. 24

SUMMARY AND RECOMMENDATIIONS...................... 26

ACKNOWLEDGMENTS........................................ 28

APPENDIX A. Experimental..................................... 29

APPENDIX B. Mixing and Transfer Modeling Calculations........... 35

APPENDIX C. Hydrogen Generation Calculations.......................... 38

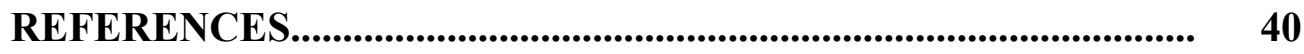




\section{LIST OF FIGURES}

1 Peanut Vial Sample of Neptunium Solution........................... 8

$2 \quad$ Temperature Profile During Neutralization......................................... 10

$3 \quad$ Neutralized Neptunium Slurry............................................................... 11

4 Cumulative Particle Size for Neutralized Neptunium Slurry........... 12

$5 \quad$ Particle Size Distribution for Neutralized Neptunium Slurry.......... 12

$6 \quad$ Neptunium Slurry Settling Test.............................................................. 15

$7 \quad$ Results of Settling Test............................................................................ 15

$8 \quad$ Racetrack Apparatus.............................................................................. 17

9 Flow Curves for Washed Sludge Mixtures............................................ 19

A-1 Calibration of Racetrack Apparatus................................................. 31

A-2 Neptunium Slurry Yield Strength Measurement............................. 33

\section{LIST OF TABLES}

I Composition of Tank 16.4 Neptunium Solution............................ 9

II Composition of Neutralized Neptunium Slurry....................... 13

III Viscosity of Neutralized Neptunium Slurries from Racetrack

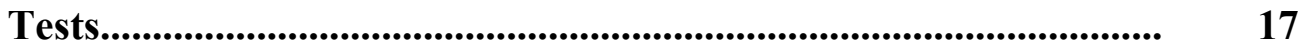

IV Yield Stress and Consistency from Washed Sludge Tests................ 18

V Calculated Settling Velocity................................................................. 20

VI Fast-Settling Slurry Correlations and Predicted Agitator Speeds.. 21

VII Calculated Transition Velocities for Slurry Transport..................... 24

VIII Hydrogen Generation Rates for Neptunium Slurry and Sludge

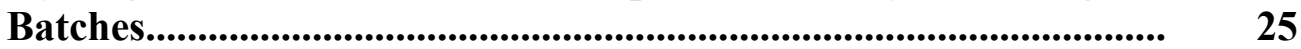

A-I Results of Racetrack Calibration and Slurry Tests.......................... 31

A-II Composition of Non-radioactive Neodymium Simulant..................... 32

A-III Rheology Flow Curve Data..................................................................... 33

A-IV Results of Bingham Plastic Model Curve Fit to Slurry Samples..... 34

B-I Required Agitator Speed to Mix Settled Neptunium Slurry.......... 36

B-II Agitator Speed Required to Suspend Insoluble Particles................... 37

C-I Hydrogen Generation Rate for Neptunium Solution............................ 38 


\title{
RESULTS OF NEPTUNIUM DISPOSAL TESTING
}

\author{
By D. D. Walker, M. R. Poirier, T. L. Fellinger, and E. K. Hansen
}

\begin{abstract}
Researchers investigated the neutralization of neptunium solution from H-Canyon Tank 16.4 and the properties of the resulting slurry. None of the results preclude the transfer of the neutralized solution to the tank farm. The following summarize the major test results of this study.
\end{abstract}

- The composition of the Tank 16.4 neptunium solution differs significantly from preliminary estimates from $\mathrm{H}$ Canyon.

- The iron concentration equals $250 \%$ of the preliminary estimate.

- The sodium concentration equals $220 \%$ of the preliminary estimate.

- The sulfate ion concentration, not reported in the preliminary analysis, equals 1.29 molar.

- Previous evaluations of the transfer feasibility or DWPF impacts based on the H-Canyon preliminary data should be reviewed in light of the composition provided in this report.

- Neutralization of the acid neptunium solution proceeds smoothly without complications.

- Metal hydroxide solids precipitate, producing a slurry containing 4 wt \% insoluble solids. The insoluble solids are largely iron hydroxide (92\%). Neptunium hydroxides or oxides comprise about $2 \%$ of the insoluble solids.

- Acid neutralization produces heat, but boiling will not occur if the slurry remains well mixed during sodium hydroxide addition.

- The rheological properties of the neptunium slurry, as precipitated at $4 \mathrm{wt} \%$ insoluble solids, will allow transfer through the tank farm. However, concentration of the insoluble solids above $4 \mathrm{wt} \%$ may cause significant problems due to increases in yield stress and consistency.

- The solids settle slowly and re-suspend easily in the $4 \mathrm{wt} \%$ slurry.

- The consistency of the $4 \mathrm{wt} \%$ slurry is 7.65 centipoise (cP) with a yield stress less than 1 Pascal $(\mathrm{Pa})$.

- Concentration to $6.7 \mathrm{wt} \%$ insoluble solids increases the yield stress and consistency, producing a slurry that does not flow through the racetrack apparatus, and suggesting potential problems during tank farm transfer.

- The neptunium slurry, when combined with actual SB2 washed radioactive sludge, yields a combined slurry with acceptable rheological properties for DWPF processing.

- Addition of the neptunium slurry to a sample of SB2 washed sludge slightly reduced the yield stress and consistency of the sludge.

- Transfer modeling indicates a minimum fluid velocity of $\sim 4 \mathrm{ft} / \mathrm{sec}$ will prevent the precipitated solids from settling in horizontal, 3-inch diameter piping. 
- Mixing calculations using various models differed in their evaluation of the adequacy of mixing in the H Canyon Tank 16.4 (proposed neutralization tank).

- Bingham plastic modeling and slow-settling solids models indicate adequate mixing in Tank 16.4 .

- Fast-settling solids models suggest inadequate mixing.

- Since testing showed the settled solids are Bingham plastic and the sheared slurry is a slow-settling Newtonian slurry, we conclude Tank 16.4 has adequate mixing.

- Combining the neptunium slurry with washed sludge will increase radiolytic hydrogen generation rates slightly $(<9 \%)$.

Evaluations of the feasibility of the transfer or the impacts on the Defense Waste Processing Facility (DWPF) vitrification process based on the preliminary estimates should be reviewed in light of the composition provided in this report. The presence of sulfate ion, which has a low solubility in glass, was not previously reported. The neutralized slurry will contain more solids and be more difficult to mix and transfer than one would predict from the preliminary estimates. Nevertheless, rheological data based on the actual, higher concentrations, supports the feasibility of the transfer. The higher than expected sodium concentration in the acidic neptunium solution amounts to only $5 \%$ more total mass of sodium transferred to the washed sludge batch. The majority of the sodium comes from the $\mathrm{NaOH}$ required for neutralization. This increase may slightly change potential impacts to the DWPF processes identified from the preliminary estimates.

This work investigated slurry properties from a single neutralization protocol (i.e., $\mathrm{NaOH}$ concentration, addition rate, and temperature profile) and limited storage times. The summary includes suggestions for additional work exploring the impact of variations in the neutralization and storage conditions on the properties of the slurry. 


\section{INTRODUCTION}

The Department of Energy decided to close $\mathrm{H}$ Canyon, including removing all process materials. During closure operations, processing of irradiated uranium fuel yields small quantities of neptunium that are being stored in Tank 16.4. The small quantity $(52 \mathrm{~kg})$ and low purity of this neptunium makes it unattractive for recovery for production of $\mathrm{Pu}-238$. Thus, the Closure Business Unit is considering disposal of these impure neptunium solutions to the tank farm. A project is in place to process through HB Line a larger amount of high purity neptunium recovered and purified in the 1980s. The recovered neptunium would likely be transferred to Oak Ridge National Laboratory for future production of Pu-238.

A preliminary engineering assessment of neptunium disposition in the SRS tank farms identified several options. ${ }^{1}$ The preferred option transfers the neptunium to a washed sludge tank. This option localizes the neptunium in a tank from which the primary outlet is vitrification in the Defense Waste Processing Facility. Transfer of neptunium to any other part of the tank farm results in an increase in the soluble neptunium in feed to the Saltstone Facility. The higher neptunium concentrations would likely exceed Saltstone waste acceptance criteria for neptunium.

However, addition of the neptunium solutions to a washed sludge tank poses several technical uncertainties. These can be divided into three categories: uncertainties in transferring a neutralized slurry from H Canyon to the washed sludge tank, changes in composition and rheological properties of the washed sludge, and changes in glass composition and processing. This task focused on preliminary answers to questions in the first two categories and included the following.

- Characterize the Tank 16.4 neptunium solution

- Neutralize portions of the solution and characterize the solids and liquid phase

- Measure the rheological properties of the neutralized slurry

- Model the slurry transport properties and estimate the flow requirements to suspend the particles during transfer.

- Calculate the impact of the neptunium slurry on hydrogen generation in the washed sludge tank.

This document reports the test results related to these items.

This work fulfills the following technical task request from High Level Waste Process Development and Integration: E. T. Ketusky, "Np Disposition Support," HLE-TTR2003-095, February 26, 2003. The work complies with the following plan: D. D. Walker, "Technical Task and Quality Assurance Plan for Neptunium Disposal Testing," WSRCRP-2003-00229, Rev.0, February 27, 2003. 


\section{RESULTS AND DISCUSSION}

\section{Characterization of Neptunium Solution}

H Canyon personnel sent thirty 10-mL peanut vials of the neptunium solution from Tank 16.4 to the Savannah River Technology Center (SRTC). Waste Processing Technology Section (WPTS) personnel combined the contents of the peanut vials in one bottle to form a composite sample. The dark, composite solution appeared to contain no solids (Figure 1). Analytical Development Section (ADS) personnel analyzed portions of the composite solution. Table I lists the results of the analyses and the composition as provided by $\mathrm{H}$ Canyon personnel. ${ }^{2}$

The concentrations of several components in the composite sample agree closely with the $\mathrm{H}$ Canyon results. For example, the neptunium, plutonium, and Cs-137 concentrations agreed within experimental uncertainties. The calculated total acid from the $\mathrm{H}$ Canyon results $($ Total Acid $=$ Free Acid $+3[\mathrm{Fe}]+4[\mathrm{Al}])$ equals $8.0 \mathrm{M}$ compared to the SRTC

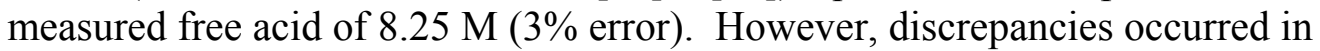
components important to disposal in the tank farm. The iron and sodium concentrations greatly exceed the $\mathrm{H}$ Canyon. Iron produces the majority of the insoluble solids in the slurry that must be transferred through the tank farm. The higher iron concentration makes the transfer more difficult and produces more impact on the contents of the washed sludge tank than one would expect from the preliminary $\mathrm{H}$ Canyon results. The higher than expected sodium concentration in the acid $\mathrm{Np}$ solution affects only slightly the total sodium transferred to the washed sludge tank. The majority of the sodium in the neutralized slurry derives from the sodium hydroxide used for neutralization. The additional sodium in the acidic Np solution contributes only 5\% to total mass of sodium in the solution transferred to the washed sludge tank. This amount is likely insignificant. Other metals (Cr, Mn, and Ni) also occur at higher concentrations than anticipated, but at concentration so low that they likely will not significantly affect the total solids in the

\section{FIGURE 1. Peanut Vial Sample of Neptunium Solution}

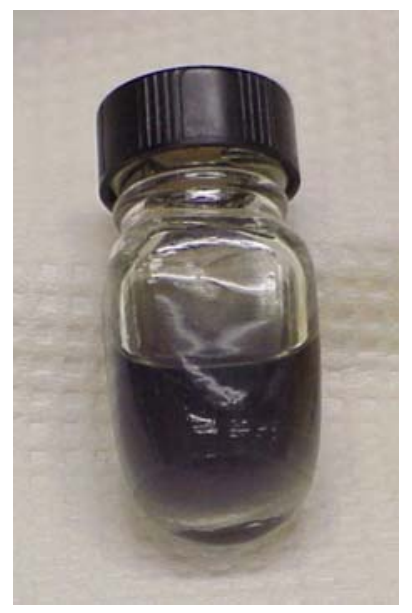


TABLE I. Composition of Tank 16.4 Neptunium Solution

Component

Total Acid

Free acid

Nitrate

Sulfate

$\mathrm{Na}$

$\mathrm{Fe}$

Al

$\mathrm{Cr}$

$\mathrm{Ni}$

$\mathrm{Mn}$

$\mathrm{Ca}$

$\mathrm{Zn}$

$\mathrm{Zr}$

$\mathrm{Hg}$

$\mathrm{Np}-237$

$\mathrm{Pu}-238$

Total U

Pu-239+240

Cs-137

Density
Concentration (M)

\begin{tabular}{cl} 
Expected* & Found** \\
\hline-- & 8.25 \\
6.4 & 4.9 \\
-- & 6.6 \\
-- & 1.29 \\
0.26 & 0.58 \\
0.28 & 0.70 \\
0.18 & 0.23
\end{tabular}

Concentration (mg/L)

40

380

1530

855

$20 \quad 218$

$80 \quad 112$

$50 \quad 54$

128

$80 \quad 111$

$13200 \quad 12800$

$\begin{array}{ll}1.15 & 1.07\end{array}$

1844

Concentration $(\mathrm{d} / \mathrm{m} / \mathbf{m L})$

$4.1 \times 10^{5} \quad 3.8 \times 10^{5}$

$2.02 \times 10^{6} \quad 2.11 \times 10^{6}$

-- $\quad 1.364 \mathrm{~g} / \mathrm{mL}$

* Reference 2.

** Error limits on these results are nominally $\pm 10 \%$, except the density $( \pm 0.003 \mathrm{mg} / \mathrm{L})$.

transfer. The uranium concentration equaled $44 \mathrm{mg} / \mathrm{L}$ compared to the expected 18 $\mathrm{mg} / \mathrm{L}$ and the enrichment exceeded the expected value (see discussion below). However, due to the low concentration and its insignificant effect on rheology, verification of the value was not pursued.

\section{Neutralization of Neptunium Solution}

Researchers neutralized several 30-mL aliquots of neptunium solution using approximately $16 \mathrm{~mL}$ of $50 \mathrm{wt} \%$ (i.e., approximately $19 \mathrm{M}$ ) sodium hydroxide solution. The duration of the $\mathrm{NaOH}$ addition was adjusted to 2.5 hours to approximate the expected addition rate in the canyon. The reaction proceeded as expected. Heat was generated, solids precipitated, and the solution color changed. Researchers observed no gas evolution or foaming.

The amount of $\mathrm{NaOH}$ required was calculated from the total acid results $(8.25 \mathrm{M}$, 
Table 1) and included enough excess to reach $1.1 \mathrm{M} \mathrm{NaOH}$ in the final neutralized solution. Subsequent titration of the $50 \mathrm{wt} \% \mathrm{NaOH}$ solution showed it contained $18 \pm 1$ molar $\mathrm{OH}^{-}$. Thus, the final excess $\mathrm{NaOH}$ concentration following neutralization averaged only $0.6 \pm 0.1 \mathrm{M}$. This closely approximates the expected value of $0.7 \mathrm{M}$ based on $18 \mathrm{M}$ $\mathrm{NaOH}$.

During the early stages of $\mathrm{NaOH}$ addition, the temperature increased approximately $15{ }^{\circ} \mathrm{C}$. Figure 2 shows the temperature profiles during two neutralizations. Based on the heat of neutralization of free acid and assuming no heat losses and a heat capacity of $1 \mathrm{cal} / \mathrm{g} /{ }^{\circ} \mathrm{C}$, the temperature increase could be as high as $60^{\circ} \mathrm{C}$. The small temperature increase observed likely results from heat losses to the atmosphere from the small reaction flask during the 2.5 hour addition. A larger volume reaction, such as in the canyon tanks, will likely experience a larger temperature increase.

Solids precipitation occurred locally during the initial addition of $\mathrm{NaOH}$, but the solids dissolved as the solution mixed. Precipitated solids became persistent after approximately 100 minutes from the start. This corresponds to addition of enough $\mathrm{NaOH}$ to neutralize the free acid. At this point, the $\mathrm{pH}$ will begin to increase rapidly, resulting in precipitation of iron and neptunium. Immediately prior to observation of persistent solids, the color of the solution changed from dark green to reddish orange. Solids precipitation caused a noticeable increase in the slurry viscosity as evidenced by a decrease in the rotational rate of the stir bar used to mix the slurry. This peaked at approximately 135 minutes and then the mixing rate increased slightly during the final 15 minutes. The improved mixing at the end possibly results due to dilution of the slurry following complete precipitation of solids or due to passing the isoelectric point (typically $\mathrm{pH} 6$ to 8 ) where slurries exhibit their most viscous properties. Figure 3 shows the reddish solids in a neutralized slurry after settling for several days.

\section{FIGURE 2. Temperature Profile during Neutralization}

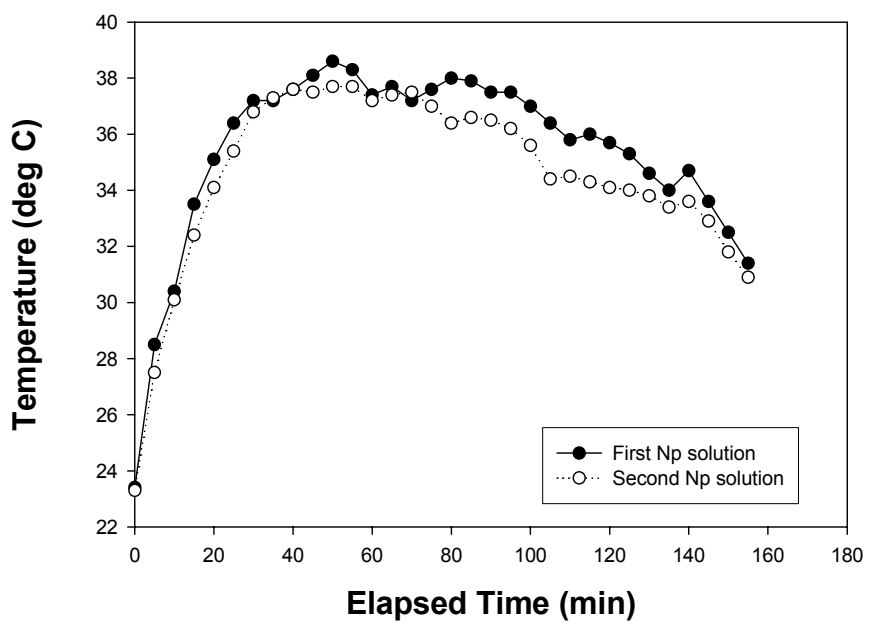


FIGURE 3. Neutralized Neptunium Slurry

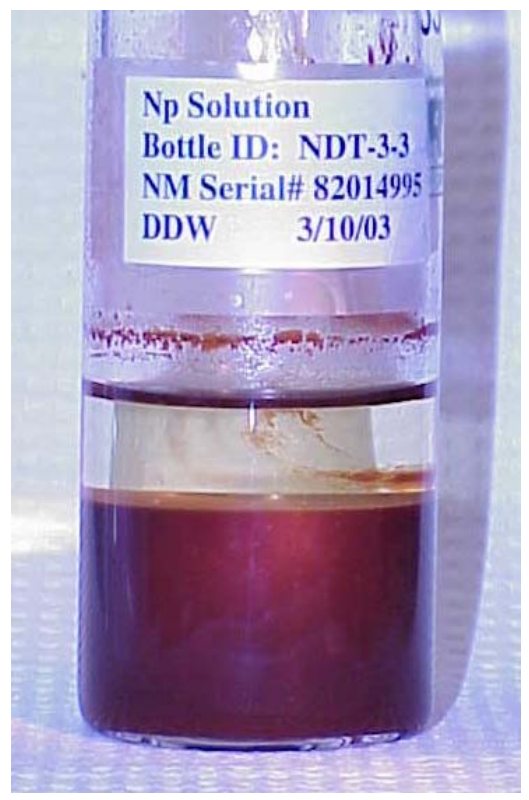

The neutralized slurry contained particles between 1 and 88 microns in diameter. Figures 4 and 5 show the size distribution. The mean diameter of the volume distribution equaled 11 microns. All of the particles are less than 88 microns. $95 \%$ of the particles are less than 31 microns, and $80 \%$ of the particles are less than 18 microns. The particle size data was used to determine the requirements for suspending the solid particles if the slurry is a fast-settling slurry and for determining the requirements for transporting the slurry from the Separations Canyon to the Tank Farm.

Following neutralization, the solids were separated from the aqueous phase by filtration, washed slightly with $0.1 \mathrm{M} \mathrm{NaOH}$, and partially dried at ambient temperature $\left(23 \pm 3{ }^{\circ} \mathrm{C}\right)$. Table II lists results of analyses performed on the filtrate and damp solids. The $\sim 13 \mathrm{wt} \%$ yield of damp solids exceeded the expected value of $\sim 4 \mathrm{wt} \%$ (see below) and indicated significant amounts of water remained. Further drying at $115^{\circ} \mathrm{C}$ reduced the solids yield to $\sim 6 \mathrm{wt} \%$. The presence of $14 \mathrm{wt} \%$ sodium in the dried solids and $\mathrm{NaNO}_{3}$ in the damp solids suggests incomplete washing occurred and soluble salts remained in the damp solids.

$\mathrm{X}$ ray diffraction analysis revealed the solids are largely amorphous, although a small fraction appeared as magnetite and sodium nitrate. Chemical analysis showed iron as the major constituent, with lesser amounts of aluminum, chromium, neptunium, nickel, and manganese. Sodium and sulfur were also present, probably due to incomplete washing to remove the aqueous phase (i.e, sodium salts of nitrate and sulfate). Some or all of the aluminum may have been present for the same reason. The composition of the solids is consistent with the expected precipitation of the metals under alkaline conditions. 
WSRC-TR-2003-00144, Rev. 0

Page 12 of 40

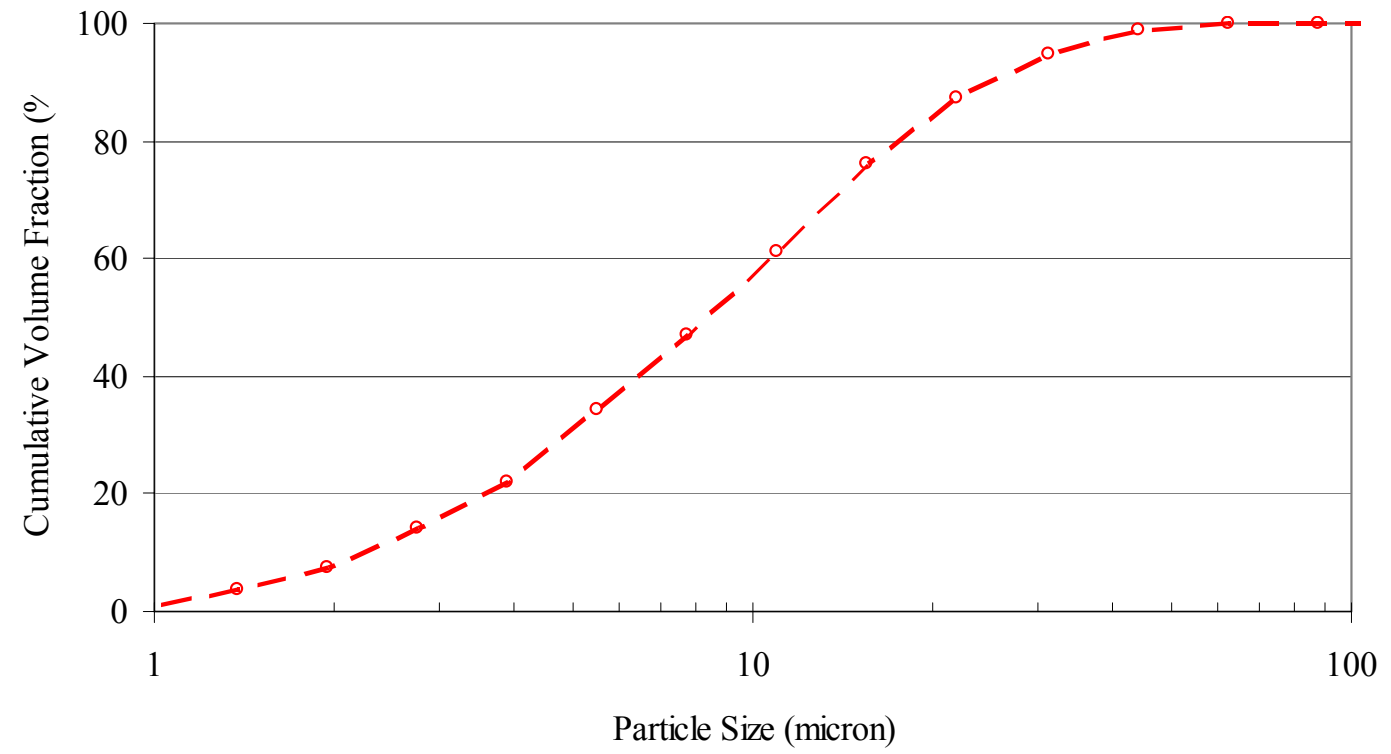

FIGURE 4. Cumulative Particle Size for Neutralized Neptunium Slurry

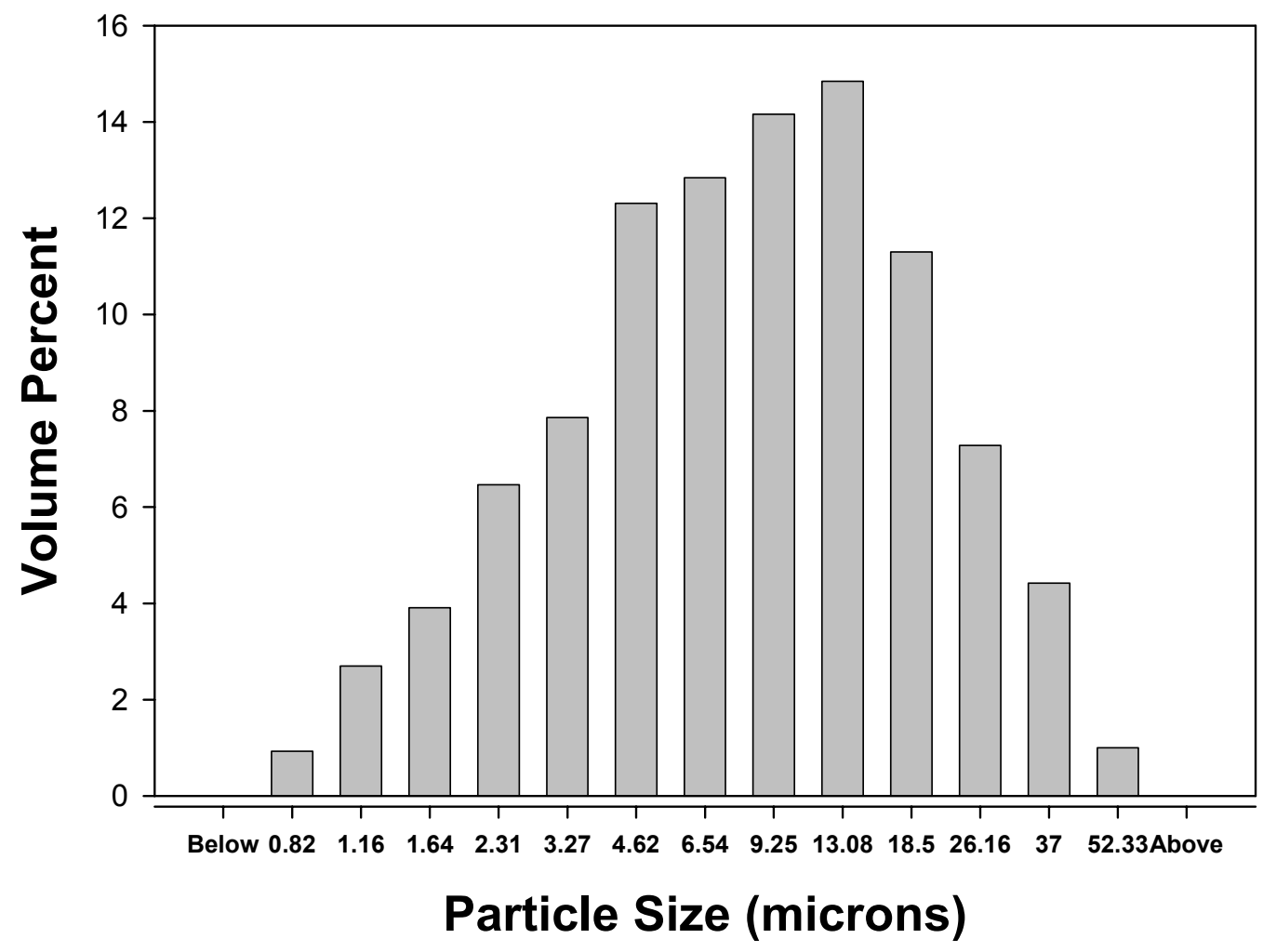

FIGURE 5. Particle Size Distribution for Neutralized Neptunium Slurry 
TABLE II. Composition of Neutralized Neptunium Slurry

\section{Solids Composition}

After drying at $23^{\circ} \mathrm{C}$ :

Yield of damp solids:

$13( \pm 1)$ wt $\%$

Phases identified

by X-ray diffraction:

magnetite, sodium nitrate

After drying to constant weight at $115^{\circ} \mathrm{C}$ (approx. 4 hours):

Weight loss on drying at $115^{\circ} \mathrm{C} \quad 54 \pm 3 \%$

Component Concentration $\quad \underline{\text { Component }}$ Concentration

$\begin{array}{lcll} & \underline{(\mathbf{w t} \%)} & & \underline{\mathbf{( w t} \%)} \\ \mathrm{Al} & 1.6 \pm 0.1 & \mathrm{Na} & 14.2 \pm 0.7 \\ \mathrm{Cr} & 1.2 \pm 0.1 & \mathrm{Ni} & 0.62 \pm 0.05 \\ \mathrm{Fe} & 29.0 \pm 2.4 & \mathrm{~S} & 2.4 \pm 0.2 \\ \mathrm{Mn} & 0.16 \pm 0.01 & \mathrm{~Np}-237 & 1.03 \pm 0.07\end{array}$

\section{Solution Composition}

\begin{tabular}{|c|c|c|c|}
\hline Component & $\frac{\text { Concentration }}{\underline{(\mathrm{M})}}$ & Component & $\begin{array}{c}\text { Concentration } \\
(\mathrm{mg} / \mathrm{L})\end{array}$ \\
\hline $\mathrm{OH}^{-}$ & $0.60 \pm 0.11$ & $\mathrm{Cr}$ & $10.4 \pm 0.6$ \\
\hline Nitrate & $4.48 \pm 0.22$ & $\mathrm{Ni}$ & $<0.2$ \\
\hline Sulfate & $0.84 \pm 0.04$ & $\mathrm{Mn}$ & $<0.1$ \\
\hline $\mathrm{Na}$ & $6.6 \pm 0.2$ & $\mathrm{Ca}$ & $0.53 \pm 0.10$ \\
\hline \multirow[t]{8}{*}{$\mathrm{Al}$} & $0.109 \pm 0.008$ & $\mathrm{Zn}$ & $0.46 \pm 0.16$ \\
\hline & & $\mathrm{Zr}$ & $<0.3$ \\
\hline & & Np-237 & $1.8 \pm 0.6$ \\
\hline & & Total U & $9 \pm 2$ \\
\hline & & U-234 & $0.7( \pm 0.2)$ \\
\hline & & U-235 & $4.0( \pm 1.0)$ \\
\hline & & U-236 & $1.2( \pm 0.3)$ \\
\hline & & U-238 & $3.3( \pm 0.7)$ \\
\hline
\end{tabular}

\section{Component}

Cs-137

Cs-134

\section{Concentration}

$\underline{(\mathrm{d} / \mathbf{m} / \mathbf{m L})}$

$1.38(0.04) \times 10^{6}$

$8.0( \pm 0.4) \times 10^{3}$

Other

Density

$1.322 \mathrm{~g} / \mathrm{mL}$

*Listed uncertainties are the standard deviation of measurements from two neutralization experiments. Analytical uncertainties are nominally $\pm 10 \%$. 
The aqueous phase analyses showed the expected loss of metals found in the solids. Iron, chromium, neptunium, nickel, and manganese precipitate as expected. In addition, the analyses showed approximately $70 \%$ of the uranium precipitated. The U-235 enrichment measured $43( \pm 10) \%$ compared to the H-Canyon preliminary results of $25 \%$ (before neutralization). The final concentration of neptunium in the filtrate equaled $1.8 \mathrm{mg} / \mathrm{L}$, much lower than the expected solubility of $\sim 100 \mathrm{mg} / \mathrm{L}{ }^{3}$ The low concentration likely reflects a non-equilibrium condition due to the rapid precipitation in the presence of a large amount of iron hydroxide. The high sulfate and nitrate concentrations in the neutralized aqueous phase require addition of 1.1 molar excess $\mathrm{NaOH}$ to meet corrosion inhibitor requirements for the tank farm. The sulfate may also impact DWPF processes.

Based on complete precipitation of iron (as $\left.\mathrm{Fe}(\mathrm{OH})_{3}\right)$, neptunium ( $\operatorname{as~}_{\mathrm{Np}} \mathrm{O}_{5}$ ), chromium (as $\left.\mathrm{Cr}(\mathrm{OH})_{3}\right)$, nickel (as $\left.\mathrm{Ni}(\mathrm{OH})_{2}\right)$, and manganese $\left(\mathrm{as}_{\mathrm{MnO}}\right)$ in the original neptunium solution, the theoretical insoluble solids concentration in the final neutralized solution equals $4.0 \mathrm{wt} \%$. The solids (by weight) are approximately $92 \%$ iron hydroxide, $4 \%$ chromium hydroxide, $2 \%$ nickel hydroxide, and 2\% neptunium oxide. Magnesium also precipitates but comprises less than $0.5 \%$ of the solids weight.

\section{Rheological Testing of Neutralized Solution}

Rheological testing included mixing tests on settled slurry, racetrack tests at different wt \% insoluble solids, and viscometer measurements on Np slurry and on Np slurry mixed with washed radioactive sludge.

\section{Mixing and Settling Tests}

Mixing tests demonstrated that the solids formed during neutralization can be resuspended after settling for up to 7 days. The experiments used a reaction vessel and stir bar sized to approximate the geometry in H-canyon Tank 16.4, and a mixing energy input less than the capability in Tank 16.4. Re-suspension occurred for slurries that settled for 3 and 7 days. In both cases, initial movement of the stir bar produced little agitation. However, within one hour, the slurry appeared well mixed with the solids fully suspended and with liquid movement throughout the sample. Since the solids settle slowly, periods longer than 7 days without agitation may result in more difficulty in resuspending the solids.

A settling test conducted in a graduated cylinder(Figure 6) produced the settling curve shown Figure 7. Solids settled rapidly during the initial 8 hours, but slowed considerably thereafter. The initial settling rate of $0.017 \mathrm{~mm} / \mathrm{sec}$ estimates the velocity of the slowest settling solids. Due to the opacity of the slurry, accumulation of solids at the bottom was not observable so no information on fast-settling solids was obtained. Two interfaces were observed during the first day. Interface 1 occurred between clear solution and slightly cloudy solution. Interface 2 , located lower than Interface 1 , occurred between the cloudy solution and the opaque slurry. After the first day, no cloudy layer was observed (Interface 1 and 2 merged). 
FIGURE 6. Neptunium Slurry Settling Test

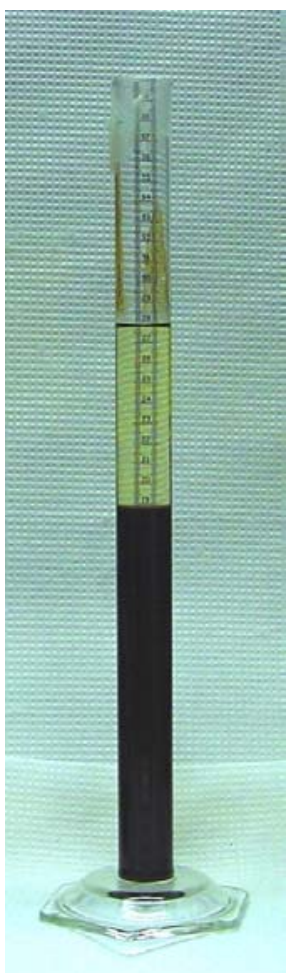

\section{FIGURE 7. Results of Settling Test}

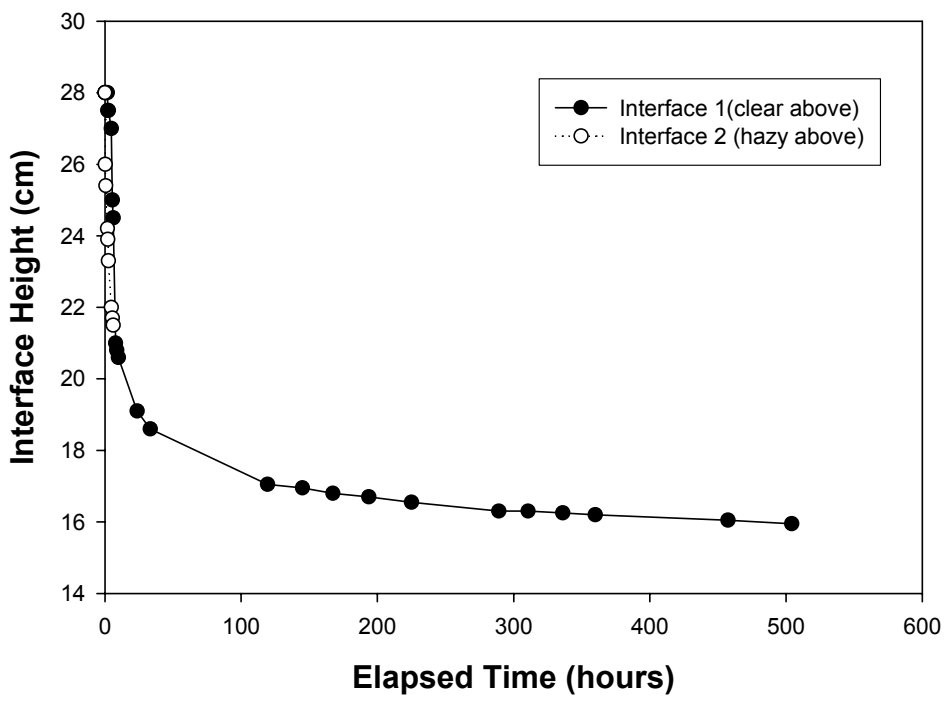




\section{Racetrack Test}

A "racetrack" apparatus (Figure 8) was constructed to demonstrate the relative flow characteristics of slurries at different solids loadings. The design of the racetrack was similar to previous testing. ${ }^{4}$ In this case, the coiled tubing was smaller in diameter and shorter in length, with a stopcock between the coil and sample holder. The time required to empty the cup was measured for various solutions. The results are a measure of the viscosity and yield stress of the slurry. The inside diameter of the glass tubing $(3 \mathrm{~mm})$ exceeds the particle diameter of the insoluble solids, thus allowing use with slurries containing particles that would plug the small diameter tubes in Ostwald or CanonFenske viscometers. Calibration of the apparatus with standards of known viscosity allowed conversion of the efflux time to viscosity.

Researchers prepared three radioactive and one non-radioactive (simulant) slurries. The non-radioactive simulant composition reflected the SRTC iron and aluminum results for the Tank 16.4 neptunium solution (Table I), but substituted an equivalent molar quantity of non-radioactive neodymium for the neptunium. Neptunium slurries at 6.7 and $2.2 \mathrm{wt} \%$ insoluble solids were prepared by allowing the solids to settle in a $4 \mathrm{wt} \%$ slurry, decanting clear supernate from one sample to concentrate the insoluble solids to $6.7 \mathrm{wt} \%$, and adding the decant solution to another slurry to dilute it to $2.2 \mathrm{wt} \%$.

Table III lists results of the racetrack tests. The neptunium slurry, as precipitated at 4.0 wt $\%$ insoluble solids, flowed smoothly through the racetrack with an efflux time corresponding to a viscosity of $7.3 \mathrm{cP}$. This value closely approximates the result from the Haake viscometer discussed below $(7.65 \mathrm{cP})$. The diluted slurry $(2.2 \mathrm{wt} \%)$ also flowed smoothly $(4.0 \mathrm{cP})$. These slurries drained with efflux times less than four minutes. In contrast, the concentrated slurry $(6.7 \mathrm{wt} \%)$ did not flow smoothly, flowed slower with time, and, after 5 minutes, the slurry did not reach the bottom of the racetrack. Personnel observed similar behavior with a simulated F-Canyon uranium slurry used in the $\mathrm{Am} / \mathrm{Cm}$ transfer program. ${ }^{2}$ The uranium slurry flowed rapidly up to about $3 \mathrm{wt} \%$ insoluble solids, but slowed rapidly at higher insoluble solids loadings.

Results from the non-radioactive neodymium simulant (3.7 wt \% insoluble solids) suggest that the simulant provides a reasonable substitute for the rheological properties of the neptunium slurry. In addition to results from the racetrack apparatus, researchers obtained two consistent viscosity measurements in a Canon-Fenske viscometer before the plugging occurred. Results from the two methods differed by $\sim 25 \%$ (5.8 cP from the racetrack; $7.5 \mathrm{cP}$ from the Canon-Fenske viscometer). This range of values for the simulant overlaps values reported for the neptunium slurry $(7.3-7.65 \mathrm{cP}$ at $4 \mathrm{wt} \%$ insoluble solids). The lower average value for the simulant may be due in part to its lower insoluble solids content compared to the neptunium slurry. 
FIGURE 8. Racetrack Apparatus

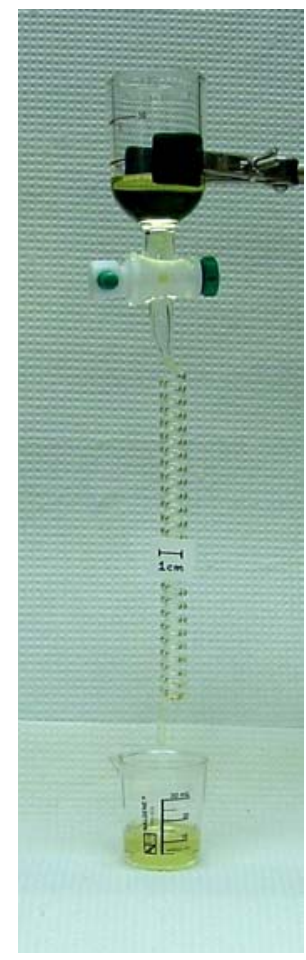

TABLE III. Viscosity of Neutralized Neptunium Slurries from Racetrack Tests

\section{Sample}

$2.2 \mathrm{wt} \%$ neptunium slurry

$4.0 \mathrm{wt} \%$ neptunium slurry

$6.7 \mathrm{wt} \%$ neptunium slurry

$3.7 \mathrm{wt} \%$ neodymium simulant

\section{$\underline{\text { Viscosity (cP) }}$}

$4.0 \pm 0.3$

$7.3 \pm 0.5$

did not flow

$5.8 \pm 0.4^{*}$

* This non-radioactive simulant was tested in a Canon-Fenske viscometer and ran twice successfully before plugging. The viscosity by this method was $7.5 \pm 0.1 \mathrm{cP}$. 


\section{Rheometer Tests on Neptunium Slurry}

Researchers measured the yield stress of a settled slurry, and the yield stress and consistency of a well-mixed slurry at $4 \mathrm{wt} \%$ insoluble solids and ambient temperature $\left(20-23^{\circ} \mathrm{C}\right)$ using rotating vane and coaxial cylinder geometries with a Haake rheometer. The yield stress of settled solids were measured using a four-vane measuring head after settling for four days. The yield stress by this method was 5.2 Pa. Researchers homogenized the sample by hand mixing with the vanes, transferred the sample to a measuring cup, installed a cylindrical rotor, and measured the flow curve (shear rate vs. shear stress). The flow curve was analyzed assuming the slurry was either a Newtonian or a Bingham plastic fluid. Detailed results are listed in Appendix A. The Newtonian viscosity of $7.65 \mathrm{cP}$ agrees closely with the racetrack results $(7.3 \pm 0.5 \mathrm{cP})$. The yield stress for the homogenized slurry was 0.21 to $0.55 \mathrm{~Pa}$. As expected, this was much lower than the yield stress for settled solids. The authors elected to treat the sheared (well mixed) slurry as Newtonian.

\section{Rheometer Test on Neptunium Slurry Mixed with Washed Radioactive Sludge}

Researchers measured flow curves on a portion of washed radioactive sludge (Sludge Batch 2$)^{5}$ mixed with $4 \mathrm{wt} \%$ neptunium slurry to determine the impact of the neptunium on the sludge rheological properties. The experiment compared flow curves for the washed sludge, sludge mixed with neptunium, and the sludge-neptunium mixture diluted with inhibited water $(0.01 \mathrm{M} \mathrm{NaOH})$. The neptunium and sludge were combined in a volume ratio corresponding to the expected transfer of 12,000 gallons of neptunium slurry into 360,000 gallons of washed sludge (volume ratio: 1:30). To account for flush water that may accompany the neptunium, a volume of $0.01 \mathrm{M} \mathrm{NaOH}$ equal to the neptunium slurry volume (i.e., volume ratios: flush water:Np slurry:washed sludge::1:1:30) was added for the final measurement. The washed sludge sample contained $17.5 \mathrm{wt} \%$ insoluble solids.

Table IV and Figure 9 show the results of modeling the slurries as Bingham plastics. The addition of the neptunium slurry and flush water thinned the sludge slurry. This is likely due to the net decrease in wt $\%$ insoluble solids caused by the two additions. All of the results fell within the DWPF operating region. ${ }^{6}$

\section{TABLE IV. Yield Stress and Consistency from Washed Sludge Tests}

\begin{tabular}{lcc}
\multicolumn{1}{c}{ Sample } & $\begin{array}{c}\text { Yield Stress } \\
\mathbf{( P a )}\end{array}$ & $\begin{array}{c}\text { Consistency } \\
(\mathbf{( \mathbf { P } )}\end{array}$ \\
Washed sludge & 7.79 & 6.0 \\
Washed sludge + Np slurry & 7.37 & 6.0 \\
Washed sludge + Np slurry + flush water & 6.53 & 5.5
\end{tabular}


FIGURE 9. Flow Curves for Washed Sludge Mixtures

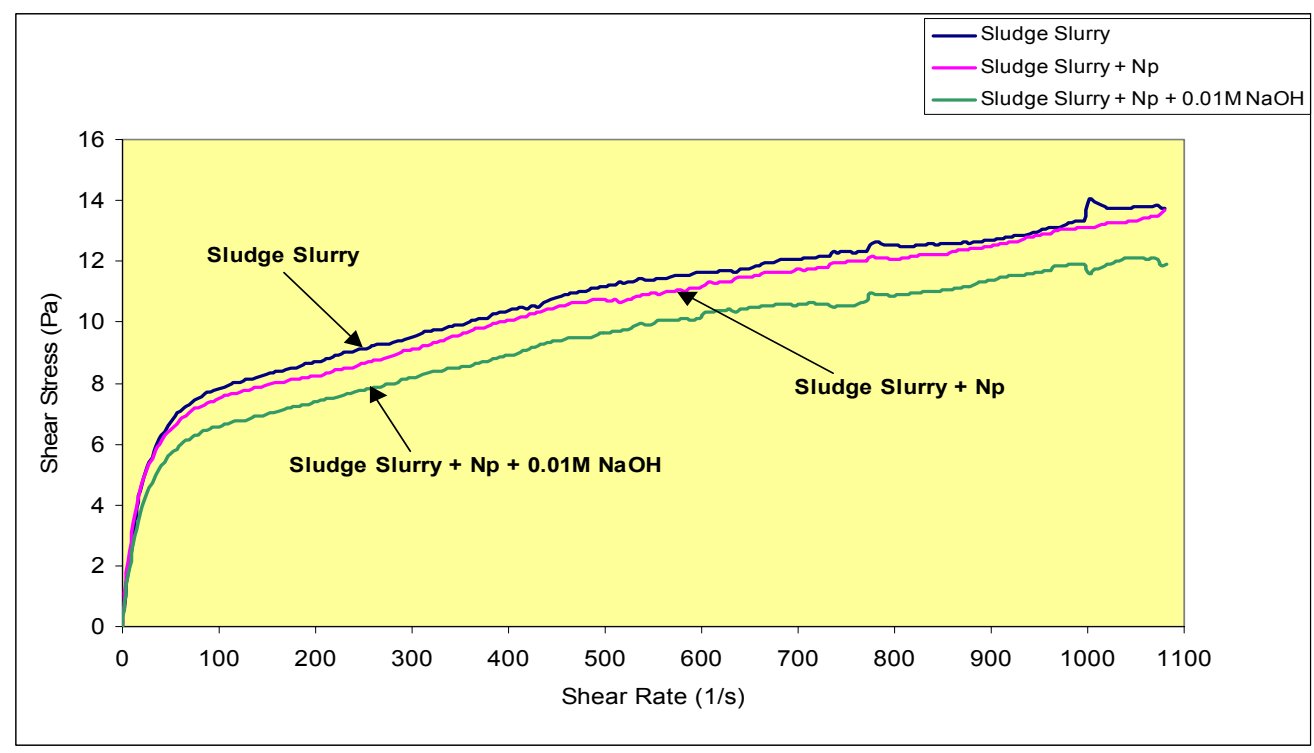

\section{Mixing and Transfer Modeling}

Mixing and transfer modeling applies to suspending particles in the neutralization tank (Tank 16.4) and maintaining particles in suspension during transfer to the tank farm. Researchers examined the applicability of Bingham plastic, slow-settling solids, and fastsettling solids models and correlations for the neutralized neptunium slurry.

\section{Agitation Requirements for Mixing Settled Neptunium Slurry}

To determine the agitation requirements for suspending the neutralized neptunium slurry, we need first to decide whether it is a Bingham plastic, a slow settling Newtonian suspension, or fast settling Newtonian suspension. If it is a Bingham plastic, then we apply the cavern model. ${ }^{7,89}$ If it is a slow settling Newtonian slurry, then we apply the guidance from Gray and Oldshue. ${ }^{10}$ If it is a fast settling Newtonian slurry, then we apply particle suspension correlations from the literature to calculate the required agitator speed. ${ }^{11,12,13,14}$ If all models predict adequate agitation with the current tank design, then we can be certain that the particles will suspend regardless of which of the three slurry types most closely approximates the neptunium slurry. However, if one or more models predicts the agitation is not adequate, then we must decide which of three types best represents the neptunium slurry.

\section{Cavern Model}

The cavern model (see Appendix B) ${ }^{7,8,9}$ predicts the requirements for mixing a Bingham plastic fluid. The model describes a system where close to the impeller the shear stresses generated by the impeller are greater than the yield stress of the slurry, and the slurry is 
well mixed. At large distances from the impeller, the slurry yield stress is larger than the shear stress generated by the impeller, and the slurry is not mixed. Appendix B contains the equations describing the cavern model.

The rheological testing of the settled slurry indicated the slurry behaves as a Bingham plastic with a yield stress of 5.2 Pa, thus justifying application of the cavern model. Given the Tank 16.4 physical dimensions and the slurry properties described in this report for a slurry that has settled for four days, the cavern model predicts an agitator speed of $58 \mathrm{rpm}$ to mix the slurry. Since the plant agitator rotates up to $67 \mathrm{rpm}$, it should be sufficient to mix this slurry. The suspension tests in which the stir bar size and agitation rate predicted by the cavern model achieved a well mixed slurry supports this conclusion.

In addition to mixing the contents of the tank, the agitator motor must have enough starting torque to move the agitator buried in settled solids. This report does not address this question, although, the yield stress for settled solids reported above is needed for the analysis of the problem.

\section{$\underline{\text { Slow-Settling Newtonian Correlations }}$}

The solids analysis, settling tests, and particle size measurements indicate the neptunium slurry is a low-concentration ( $4 \mathrm{wt} \%$ insoluble solids), slow settling suspension $(0.017$ $\mathrm{mm} / \mathrm{sec}$ ) with small particles ( $<88$ micron). Rheological testing of the well mixed slurry indicated a yield stress $(0.21$ to $0.55 \mathrm{~Pa})$ small enough to allow modeling as a Newtonian fluid. Work by Gray and Oldshue demonstrated that slurries with these characteristics and particle settling velocities less than $2.5 \mathrm{~mm} / \mathrm{sec}$ suspend easily and uniformly with impeller stirred tanks. ${ }^{10}$ Table V shows the calculated settling velocity for four particle sizes in the range found for the neptunium slurry. Since the settling velocity of the largest particles (88 microns) at the highest particle density $(5.24 \mathrm{~g} / \mathrm{mL})$ is less than 2.5 $\mathrm{mm} / \mathrm{sec}$, these particles should suspend easily with the current agitator design.

\section{TABLE V. Calculated Settling Velocity}

\begin{tabular}{lll}
$\begin{array}{c}\text { Particle Size } \\
(\mu)\end{array}$ & \multicolumn{1}{c}{$\begin{array}{c}\text { Calculated Settling } \\
\text { Velocity }(\mathbf{f t} / \mathbf{s})\end{array}$} & \multicolumn{1}{c}{$\begin{array}{c}\text { Calculated Settling } \\
\text { Velocity }(\mathbf{m m} / \mathbf{s})\end{array}$} \\
\hline 18 & 0.00029 & 0.087 \\
31 & 0.00086 & 0.26 \\
62 & 0.0034 & 1.0 \\
88 & 0.0069 & 2.1
\end{tabular}


$\underline{\text { Fast-Settling Newtonian Correlations }}$

Since an experimentally measured settling rate for the fastest settling particles was unavailable, we examined four fast-settling particle suspension correlations using the same particle size and density data used in the slow-settling and Bingham plastic models. The correlations apply to fast-settling insoluble solids in tanks mixed with agitators, and yield the agitator speed required to "just suspend" all of the particles (i.e., no particles remains stationary on the tank bottom for more than one second). This analysis attempted to show the adequacy of the existing mixing system even if the particles settled rapidly.

Table VI lists the correlations and the results of the analysis for particles within the size and density range of the neptunium slurry. The results of the four correlations agree within $\pm 30 \%$ of their average, but they do not predict the existing mixing system is adequate. The correlations predict that an agitator speed greater than $67 \mathrm{rpm}$ is needed to suspend all but the smallest particles with the lowest density.

Additional tests to measure settling rates for the largest particles and larger scale (6" diameter tank) mixing tests could resolve the issue. However, since the fast settling correlations generally derive from tests using larger particles than found in the neptunium slurry, and since the rheological testing and settling tests indicate the settled slurry behaves as a Bingham plastic and the sheared slurry is a slow-settling Newtonian slurry, we conclude adequate mixing exists in Tank 16.4.

TABLE VI. Fast-Settling Slurry Correlations and Predicted Agitator Speeds

\begin{tabular}{|c|c|c|c|c|c|}
\hline \multicolumn{6}{|c|}{ Correlation } \\
\hline & & $\begin{array}{r}\text { Shamlou } \\
\text { (Ref. 11) }\end{array}$ & $\begin{array}{l}\text { Baldi } \\
\text { (Ref. 12) }\end{array}$ & $\begin{array}{l}\text { Zwietering } \\
\text { (Ref. 13) }\end{array}$ & $\begin{array}{l}\text { Chapman } \\
\text { (Ref. 14) }\end{array}$ \\
\hline $\begin{array}{l}\text { Particle } \\
\text { Density } \\
\text { (g/mL) }\end{array}$ & $\begin{array}{l}\text { Particle } \\
\text { Size } \\
\text { (micron) }\end{array}$ & \multicolumn{4}{|c|}{ Agitator Speed (rpm) } \\
\hline 5.24 & 88 & 230 & 198 & 143 & 181 \\
\hline 5.24 & 62 & 217 & 187 & 133 & 172 \\
\hline 5.24 & 31 & 193 & 166 & 116 & 155 \\
\hline 5.24 & 18 & 176 & 152 & 104 & 143 \\
\hline 3.6 & 88 & 175 & 151 & 112 & 146 \\
\hline 3.6 & 62 & 165 & 142 & 104 & 138 \\
\hline 3.6 & 31 & 147 & 127 & 91 & 125 \\
\hline 3.6 & 18 & 134 & 116 & 81 & 115 \\
\hline 2.4 & 88 & 121 & 104 & 80 & 108 \\
\hline 2.4 & 62 & 114 & 98 & 75 & 103 \\
\hline 2.4 & 31 & 101 & 87 & 65 & 92 \\
\hline 2.4 & 18 & 92 & 80 & 58 & 85 \\
\hline 2.0 & 88 & 96 & 82 & 65 & 90 \\
\hline 2.0 & 62 & 90 & 78 & 61 & 85 \\
\hline 2.0 & 31 & 80 & 69 & 53 & 77 \\
\hline 2.0 & 18 & 73 & 63 & 47 & 71 \\
\hline
\end{tabular}




\section{Slurry Transport}

The technical literature contains numerous correlations for predicting minimal velocities to maintain solids in suspension during transfers. Several of these were applied to the neptunium slurry based on the following information.

- The particle density is $3.6 \mathrm{~g} / \mathrm{ml} \mathrm{g} / \mathrm{cc}$.

- The fluid density is $1.322 \mathrm{~g} / \mathrm{cc}$.

- The fluid viscosity is $7.65 \mathrm{cp}$.

- The particle concentration is 5 vol \% insoluble solids.

- The pipe diameter is 3 inch.

- The particle size is $18 \mu, 31 \mu, 62 \mu$, and $88 \mu$.

Solid-liquid horizontal flow occurs in several different flow regimes. ${ }^{15,16,17,18}$ The primary parameters influencing flow regimes are velocity, fluid density, particle size, and particle density. The common flow regimes are pseudo-homogeneous suspensions, heterogeneous suspensions, heterogeneous suspensions with sliding beds, and stationary beds. Pseudo-homogeneous suspensions occur at high velocities with small particles. The particles move at the same velocity as the fluid with a uniform distribution across the pipe. With slower velocities and larger particles, heterogeneous suspensions occur. The concentration of particles across the pipe is not uniform, and the particle velocity is slightly less than the fluid velocity. At low velocities with large particles, a heterogeneous suspension with a sliding bed occurs. Particles in upper part of the pipe are in suspension and move with the liquid, while particles in the bottom of the pipe form a sliding bed of solids which moves at a slower, uniform rate. At very low velocities with large particles, a stationary bed occurs. The upper part of the pipe contains a suspension, while the lower part contains a deposit, the surface layers of which move.

The conditions at which sliding and stationary beds occur are of interest because these conditions are normally undesirable. A sliding bed can cause substantial pipe abrasion. Sliding and stationary beds lead to low transport efficiencies. The transition between a heterogeneous suspension and a heterogeneous suspension with a sliding bed is often called the deposition (or critical) velocity or re-suspension velocity, depending on whether the velocity is decreasing or increasing. ${ }^{15}$ The axial velocity in a transfer line should be greater than the deposition velocity or re-suspension velocity. If possible, slurry transfers should occur as heterogeneous suspensions. ${ }^{19}$

The Durand equation ${ }^{20,21}$ is frequently employed to calculate minimum transport velocities (i.e. for heterogeneous suspensions) in horizontal pipelines. The correlation was developed for coarse particles, and it does not account for differences in particle size. Equation [1] describes the correlation

$$
v_{t}=F[2 g(s-1) D]^{1 / 2}
$$


where $\mathrm{v}_{\mathrm{t}}$ is the minimum transport velocity, $\mathrm{F}$ is an empirical constant that varies between 0.4 and $1.5, \mathrm{~s}$ is the ratio of particle density to fluid density, and $\mathrm{D}$ is the pipe diameter. Using a value of 1.5 for F, 3.6 for $\mathrm{s}$, and 3 inches for the pipe diameter, the calculated minimum transport velocity is $7.8 \mathrm{ft} / \mathrm{sec}$. This correlation does not enable one to calculate the transition between a heterogeneous suspension with a sliding bed and a stationary bed. Additionally, the Durand equation is not sensitive to the size of the particles, which is a factor when transporting settling slurries in a pipe.

Wasp ${ }^{22}$ added a correction to the Durand equation to account for the influence of particle size $\left(d_{p}\right)$. Using this correction, the modified Durand equation is described by Eqn. [2].

$$
\mathrm{v}_{\mathrm{t}}=\mathrm{F}[2 \mathrm{~g}(\mathrm{~s}-1) \mathrm{D}]^{1 / 2}\left(\mathrm{~d}_{\mathrm{p}} / \mathrm{D}\right)^{1 / 6}
$$

This correlation does not enable one to calculate the transition between a heterogeneous suspension with a sliding bed and a stationary bed. Using this correlation, the required transport velocity is $1.9-2.5 \mathrm{ft} / \mathrm{s}$.

Turian et. al reviewed a collection of 864 experimental critical velocity data and developed the following correlation (Equation [3]).

$\mathrm{v}_{\mathrm{t}}=[2 g D(s-1)]^{0.5}(1.7951) C^{0.1087}(1-C)^{0.2501}\left\{\frac{D \rho[g D(s-1)]^{0.5}}{\mu}\right\}^{0.00179}\left(\frac{d_{p}}{D}\right)^{0.06623}$

where $\mathrm{C}$ is particle volume concentration. ${ }^{23}$ This correlation predicts the transition velocity equals $3.9-4.3 \mathrm{ft} / \mathrm{s}$.

Another correlation that can be applied is the one developed by Walton and described by Equation [4].

$$
\mathrm{v}_{\mathrm{t}}=v_{s} \frac{71.2}{\operatorname{Re}_{c}^{*}}\left(\frac{D}{d_{p}}\right)\left(\frac{\mu}{\rho D}\right)^{1 / 3}
$$

where $\mathrm{Re}_{\mathrm{c}}$ * is the critical Reynolds number, which is a function of particle concentration. $^{22}$ For a particle volume concentration of 5\%, its value is 7.62. Applying the Walton correlation, one calculates the transition velocity is $0.8-1.1 \mathrm{ft} / \mathrm{s}$.

Table VII summarizes the results. The most conservative approach for determining the minimum transport velocity for a heterogeneous suspension would be to select the maximum value from Table VII $(7.8 \mathrm{ft} / \mathrm{sec})$.

A less conservative approach would eliminate the results of the Durand correlation since it does not account for particle size and was developed for large particles. Using the most conservative of the remaining correlations (Turian) yields a transition velocity of $3.9-$ $4.3 \mathrm{ft} / \mathrm{s}$. 
TABLE VII. Summary of Minimum Transport Velocity Calculations.

\begin{tabular}{|l|c|c|c|c|}
\hline Correlation & \multicolumn{4}{|c|}{ Minimum Transport Velocity (ft/sec) } \\
\hline & $\mathbf{4 8} \boldsymbol{\mu}$ & $\mathbf{3 1} \boldsymbol{\mu}$ & $\mathbf{6 2} \boldsymbol{\mu}$ & $\mathbf{8 8} \boldsymbol{\mu}$ \\
\hline Durand & 7.8 & 7.8 & 7.8 & 7.8 \\
\hline Wasp & 1.9 & 2.1 & 2.4 & 2.5 \\
\hline Walton & 0.8 & 0.9 & 1.0 & 1.1 \\
\hline Turian et.al. & 3.9 & 4.0 & 4.2 & 4.3 \\
\hline
\end{tabular}

Since the slurry is composed of a mixture of particle sizes, the fine particles that are easily suspended will reduce the settling rate of the coarse particles and thereby reduce the minimum transport velocity.

\section{Hydrogen Generation in Washed Sludge}

The addition of the neutralized neptunium slurry to a washed sludge batch will increase the radiolytic hydrogen generation rate. Hydrogen forms from the degradation of water by the absorption of radiolytic decay energy. Table VIII lists the results of a preliminary estimate of radiolytic hydrogen generation in the neptunium slurry and in the washed sludge-neptunium combination. The calculation follows a similar assessment made for americium/curium addition to Sludge Batch $3 .^{24}$ The calculation includes the following major assumptions.

- All the decay energy is adsorbed by water in the waste tank.

- The hydrogen yield $\left(\mathrm{G}_{(\mathrm{H} 2)}\right)$ is 0.45 molecules $/ 100 \mathrm{eV}$ for beta/gamma radiation and 1.6 molecules $/ 100 \mathrm{eV}$ for alpha radiation.

- 12,700 gallons of neptunium solution of the composition listed in Table I is transferred to the sludge tank. This includes 8,300 gallons of the current inventory (containing $34 \mathrm{~kg} \mathrm{~Np}$ ) and an additional 4,400 gallons (containing $18 \mathrm{~kg} \mathrm{~Np}$ ) of planned additions.

- 359,000 gallons of washed sludge in Sludge Batch 2 with the radionuclide inventory listed in Appendix C or Sludge Batch 3 with radionuclide inventory listed in Reference 4.

As shown in Table VIII, addition of the neptunium slurry contributes only $8.2 \%$ to the hydrogen generation rate in Sludge Batch 2 and only $0.21 \%$ to Sludge Batch 3. 
TABLE VIII. Hydrogen Generation Rates for Neptunium Slurry and Sludge Batches

Slurry

Neptunium solution

Sludge Batch 2

Sludge Batch $2+$ Neptunium solution Sludge Batch 3

Sludge Batch $3+$ Neptunium solution
$\mathrm{H}_{2}$ Generation Rate Increase Due to

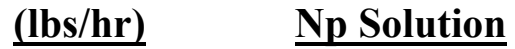
$8.65 \times 10^{-5}$
$1.60 \times 10^{-3}$
$1.66 \times 10^{-3}$
$4.02 \times 10^{-2}$
$4.025 \times 10^{-2}$
$8.2 \%$
$0.21 \%$ 


\section{SUMMARY AND RECOMMENDATIONS}

Researchers investigated the neutralization of neptunium solution from H-Canyon Tank 16.4 and the properties of the resulting slurry. None of the results preclude the transfer of the neutralized solution to the tank farm. The following summarize the major test results of this study.

- The composition of the Tank 16.4 neptunium solution differs significantly from preliminary estimates from $\mathrm{H}$ Canyon.

- The iron concentration equals $250 \%$ of the preliminary estimate. The slurry will contain more insoluble solids and be more difficult to transfer than one would estimate from the preliminary results. Rheology test results support the feasibility of the transfer at the higher concentration.

- The sodium concentration equals $220 \%$ of the preliminary estimate. This contributes $5 \%$ more sodium to the washed sludge batch than one would estimate from the preliminary results. This increase may slightly impact the DWPF processes.

- Previous evaluations of the transfer feasibility or DWPF impacts based on the H-Canyon preliminary data should be reviewed in light of the composition provided in this report.

- Neutralization of the acid neptunium solution proceeds smoothly without complications.

- Metal hydroxide solids precipitate, producing a slurry containing $4 \mathrm{wt} \%$ insoluble solids. The insoluble solids are largely iron hydroxide (92\%). Neptunium hydroxides or oxides comprise only $2 \%$ of the insoluble solids.

- Acid neutralization produces heat, but boiling will not occur if the slurry remains well mixed during sodium hydroxide addition.

- The rheological properties of the neptunium slurry (as precipitated at $4 \mathrm{wt} \%$ insoluble solids) will allow transfer through the tank farm. However, concentration of the insoluble solids above $4 \mathrm{wt} \%$ may cause significant problems due increased consistency and yield stress.

- The solids settle slowly and re-suspend easily in the $4 \mathrm{wt} \%$ slurry.

- The consistency of the $4 \mathrm{wt} \%$ slurry is $7.65 \mathrm{cP}$ with a yield stress less than $1 \mathrm{~Pa}$.

- Concentration to $6.7 \mathrm{wt} \%$ insoluble solids increases the yield stress and consistency, producing a slurry that does not flow through the racetrack apparatus, and suggesting potential problems during tank farm transfer.

- The neptunium slurry, when combined with the actual SB2 washed radioactive sludge, yields a combined slurry with acceptable rheological properties for DWPF processing.

- Addition of the neptunium slurry to a sample of SB2 washed sludge slightly reduced the yield stress and consistency of the sludge.

- Transfer modeling indicates a minimum fluid velocity of $\sim 4 \mathrm{ft} / \mathrm{sec}$ will prevent the precipitated solids settling in horizontal, 3-inch diameter piping. 
- Mixing calculations using various model differed in their evaluation of the adequacy of mixing in the H Canyon Tank 16.4 (proposed neutralization tank).

- Bingham plastic modeling and slow-settling Newtonian slurry mixing guidelines indicate adequate mixing in Tank 16.4.

- Fast-settling solids correlations suggest inadequate mixing for the large particles.

- Since testing showed the settled solids are Bingham plastic and the sheared slurry is a slow-settling Newtonian slurry, we conclude Tank 16.4 has adequate mixing.

- Combining the neptunium slurry with washed sludge will increase radiolytic hydrogen generation rates slightly $(<9 \%)$.

The following items are suggested for further investigation to ensure an adequate technical basis for the transfer of neptunium solution to the tank farms.

- Effects of neutralization parameters on slurry properties.

The present study neutralized neptunium solutions under one set of conditions (fixed addition rate and temperature profile). Neutralization in Tank 16.4 will likely occur at higher temperature and may yield a slurry with different properties. This work could likely use an appropriate simulated waste solution rather than actual neptunium solution from Tank 16.4.

- Effects of aging on neutralized neptunium slurry.

The present study includes data limited to storage for 7 days at ambient temperature. Results from the $\mathrm{Am} / \mathrm{Cm}$ program ${ }^{4}$ and other studies ${ }^{25}$ showed longer storage times at higher temperature may adversely affect the rheological properties.

Although of lesser importance than the items listed above, the following studies would provide additional information confirming the acceptability of the neptunium slurry transfer to the tank farm.

- Investigate rheological properties between $4 \mathrm{wt} \%$ and $7 \mathrm{wt} \%$ insoluble solids. The present study showed that insoluble solids content at $6.7 \mathrm{wt} \%$ will likely prove unsuitable for transfer. Additional work between 4 and $7 \mathrm{wt} \%$ could more closely define the limit of acceptable solids loadings should the composition of the neptunium solution change during future canyon operations.

- Investigate rate of dissolution of $\mathrm{Np}$ from solids.

The present study showed that, shortly after precipitation, the neptunium concentration in solution was less than expected from solubility data. Additional work could determine whether the neptunium returns to solution. This could be useful information in evaluating alternatives to the current plan of putting the neptunium in a washed sludge tank. 
- Settling rate for large particles and large scale mixing test.

A settling rate test for the fastest-settling particles in the neptunium slurry, or larger scale (6" diameter tank) mixing tests using an appropriate simulated slurry could resolve the question of adequacy of the Tank 16.4 mixing system.

\section{ACKNOWLEDGMENTS}

The authors thankfully acknowledge the contribution of Betty H. Croy (SRTC) who performed the experiments described in this report. In addition, we thank Edward T. Ketusky (Process Engineering) for helpful discussions of the objectives and results, and W. Glynn Dyer (H Area Technical Support) who arranged the sample, and provided valuable information about $\mathrm{F}$ Canyon facilities and processes. 


\section{APPENDIX A \\ Experimental}

\section{Characterization of Neptunium Solution}

The SRS H-Canyon personnel provided a sample of neptunium solution from Tank 16.4. Thirty peanut vials containing approximately $10 \mathrm{~mL}$ each were received on Feb 25, 2003, and combined in one bottle yielding $300 \mathrm{~mL}$ of sample. The combined sample produced a penetrating radiation field of less than $5 \mathrm{mrem} / \mathrm{hr}$ and was stored in a glove box. Researchers measured the densities of the solution at ambient temperature $\left(23 \pm 5^{\circ} \mathrm{C}\right)$ using a $25-\mathrm{mL}$ volumetric flask and an analytical balance $( \pm 0.001 \mathrm{~g})$. SRTC Analytical Development Section personnel analyzed portions of the composite sample using routine methods.

\section{Neutralization of Neptunium Solution}

Researchers neutralized several $30-\mathrm{mL}$ and one $60-\mathrm{mL}$ aliquot of the acidic neptunium solution. The neptunium solution was measured using a graduated cylinder and a more exact measurement was obtained by weighing the delivered amount of neptunium solution and the solution density measured previously $(1.364 \mathrm{~g} / \mathrm{mL})$. Concentrated $\mathrm{NaOH}$ solution $(18 \pm 1 \mathrm{M}$, density $1.513 \mathrm{~g} / \mathrm{mL}$ ) was prepared from reagent grade $\mathrm{NaOH}$ pellets and the final concentration was verified by standard acid titration. The neutralization occurred in Erlenmeyer flasks or reaction flasks scaled to the F-Canyon Tank 16.4 proportions with mixing provided by a stir bar. $\mathrm{NaOH}$ solution was measured in a graduated cylinder and was added to the neptunium solution in $0.1 \mathrm{~mL}$ increments at time intervals. The addition occurred over 1-2.5 hours, similar to the expected duration in F-Canyon operations. The temperature of the solution was measured using a stainless steel thermometer with digital readout (Control Company, ID \#20057190). The accuracy $\left( \pm 0.3{ }^{\circ} \mathrm{C}\right)$ was verified at 20 and $45^{\circ} \mathrm{C}$ against a NIST traceable thermocouple. The slurry was filtered using 0.45 micron nylon disposable filters. Portions of the light yellow filtrate were sent for analysis, including a density measurement $(1.322 \mathrm{~g} / \mathrm{mL})$. The solids were washed with $0.1 \mathrm{M} \mathrm{NaOH}$ and dried at ambient temperature $\left(23 \pm 3^{\circ} \mathrm{C}\right)$ by drawing air through the filter for 4 days. The weight of the damp solids was still decreasing after 4 days. The solids were transferred to a tightly capped polyethylene bottle. Portions of the damp solids were analyzed by x-ray diffraction and scanning electron microscope methods. The weight loss on drying at $115^{\circ} \mathrm{C}$ was $47 \pm 4 \mathrm{wt} \%$. Portions of the dried solids dissolved in aqua regia by heating slightly for 5 minutes. The solution was analyzed to determine metal content.

The particle size distribution of a neptunium slurry was measured using a Microtrac Model 2 particle size analyzer. The slurry was diluted to the required solids concentration using 0.1 molar $\mathrm{NaOH}$. 


\section{Rheological Testing of Neutralized Solution}

\section{Mixing and Settling Tests}

Neutralization of $30 \mathrm{~mL}$ portions of slurry were conducted in a $3.95-\mathrm{cm}$ diameter glass reaction vessel scaled to the dimensions of H-Canyon Tank 16.4 (6 ft diameter, 850 gallons working volume). Stirring was provided by a $1.9 \mathrm{~cm}$ long x $0.8 \mathrm{~cm}$ diameter magnetic stir bar (compared to tank stirring provided by a 24" diameter impeller at 67 $\mathrm{rpm})$. The appropriate rotational rate for the stir bar (1100 rpm) compared to Tank 16.4 impeller was calculated from the cavern model (see below). A Compact Instruments Limited Model CT6/LSR laser tachometer verified the rotation rate provided by the magnetic stir plate was 400-500 rpm.

After neutralizing, the slurry samples were allowed to settle for either 3 or 7 days. The glass reaction vessel was lifted above the stir plate, the stir plate adjusted to provide a stir rate of $400 \mathrm{rpm}$, and then the reaction vessel was lowered onto the plate. The initial stirring rate was less than $400 \mathrm{rpm}$, but gradually increased with time. Initially, the stirring produced only a pulsing motion at the surface and most of the sample did not appear to move. After approximately one hour, the slurries appeared to be moving smoothly at the walls throughout the vessel with all of the solids suspended, and a vortex was apparent at the surface.

The settling test was conducted in a $2.5-\mathrm{cm}$ diameter $\mathrm{x} 30 \mathrm{~cm}$ tall glass cylinder marked with a centimeter scale. Approximately $90 \mathrm{~mL}$ of $4 \mathrm{wt} \%$ insoluble solids slurry were mixed and added to the cylinder. Periodically the height of the interface between clear liquid and the settling solids was recorded. During the first day, the slurry separated into three zones: a perfectly clear zone at the top, a slightly cloudy zone in the middle, and an opaque zone at the bottom. On the second day, the slightly cloudy zone was absent, leaving only a clear zone and an opaque zone. The opaque zone was too optically dense to observe accumulation of settled solids at the bottom. A settling rate for the slowsettling solids, $0.017 \mathrm{~mm} / \mathrm{sec}$ was calculated from the data at the start time $(28.0 \mathrm{~cm})$ and after 20 minutes $(26.0 \mathrm{~cm})$.

\section{Racetrack Tests}

The SRTC glass shop personnel constructed a racetrack apparatus (Figure 7) for demonstrating the relative flow characteristics of slurries at different solids loadings. The glass apparatus consisted of a reservoir at the top to hold the slurry sample, a stopcock to initiate flow, and a coiled section through which the slurry flows. The coiled tubing ( $3 \mathrm{~mm}$ inside diameter) measured $15.5 \mathrm{~cm}$ long and $2.2 \mathrm{~cm}$ diameter and contained 24 loops. A measured sample was placed in the reservoir and the stopcock opened. The time required for the reservoir to drain was measured by a stopwatch. Initial runs with a new fluid and dry racetrack yielded significantly higher efflux times compared to subsequent runs and were not included in the data reduction. All tests were conducted at ambient temperature $\left(21 \pm 2{ }^{\circ} \mathrm{C}\right)$. After determining the efflux time was linear with samples sizes 
between 10 and $30 \mathrm{~mL}$, samples of $15( \pm 3) \mathrm{mL}$ were used in further testing and the efflux times were linearly corrected to a $15 \mathrm{~mL}$ sample volume. The racetrack was calibrated with four solutions: water, two silicone oil standards (Cole-Parmer, Viscosity Reference Standards S3 and S6), and a salt solution (3 $\mathrm{M} \mathrm{NaOH}$ and $3 \mathrm{M} \mathrm{NaNO}_{3}$ ). The viscosity of the salt solution was measured in a calibrated Cannon-Fenske viscometer (Cannon Instrument Co., Model 50, Serial \#U-428). Table A-I and Figure A-1 show the results of the racetrack calibration for $15-\mathrm{mL}$ sample volumes.

\section{TABLE A-I. Results of Racetrack Calibration and Slurry Tests}

\section{Fluid}

Water linearity test

water, $9.55 \mathrm{~mL}$

water, $19.55 \mathrm{~mL}$

water, $29.55 \mathrm{~mL}$

Calibration data

water

S3 silicone oil

S6 silicone oil

salt solution

$\begin{gathered}\text { Efflux time } \\ \text { (sec) }\end{gathered}$
$22.51 \pm 0.17$
$48.06 \pm 0.81$
$70.28 \pm 0.92$

36.1

94.1

209.3

57.2

\section{Density}

$\underline{(\mathrm{g} / \mathrm{mL})}$

\section{Dynamic}

Viscosity (cP)

Slurries

Neodymium simulant

$143.5 \pm 8.0$

1.0

3.7

8.5

Neptunium slurry, 2.2 wt \%

$101 \pm 8$

$180 \pm 11$

1.229

2.7

$4.0 \mathrm{wt} \%$

$6.7 \mathrm{wt} \%$

$\begin{array}{ll} & 5.8 \pm 0.3 \\ 1.322 & 4.0 \pm 0.3 \\ 1.322 & 7.3 \pm 0.5\end{array}$

Did not flow through racetrack.

FIGURE A-1. Calibration of Racetrack Apparatus

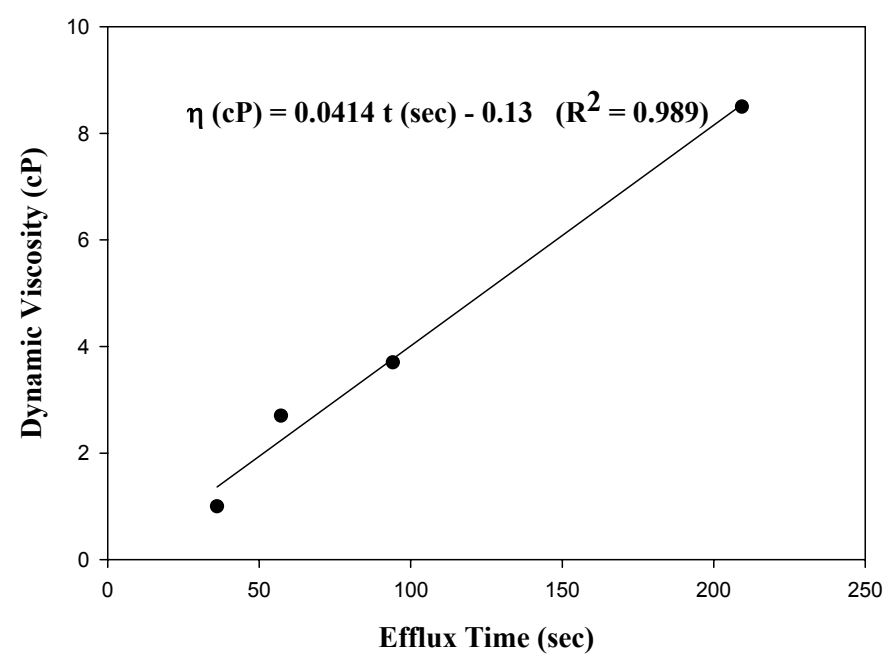


Researchers used the racetrack apparatus to measure the viscosity of a non-radioactive simulated slurry and three radioactive neptunium slurries. The simulant was prepared as an acid solution with the composition shown in Table A-II. Portions were neutralized by the process described for the neptunium slurry with similar results. Radioactive neptunium slurries at 6.7 and $2.2 \mathrm{wt} \%$ insoluble solids were prepared by allowing the solids to settle in a $4 \mathrm{wt} \%$ slurry (initial volume $90 \mathrm{~mL}$ ), decanting clear supernate ( $31 \mathrm{~mL}$ ) to concentrate the insoluble solids to $6.7 \mathrm{wt} \%$, and adding the decant solution to another $4 \mathrm{wt} \%$ slurry (initial volume $45 \mathrm{~mL}$ ) to dilute it to $2.2 \mathrm{wt} \%$. Table A-I lists results of the racetrack tests with the slurry samples.

\section{Rheometer Measurements on Neptunium Slurry}

SRTC personnel measured the yield stress of settled slurry with a Haake Model RV20/M5 rheometer. Prior to performing the measurements, the RV20/M5 rheometer was checked using a N35 viscosity $\left(50.49 \mathrm{cP}\right.$ at $\left.25^{\circ} \mathrm{C}\right)$ oil standard. The measured viscosity was $51.9 \mathrm{cP}$ at $25^{\circ} \mathrm{C}$.

The neptunium slurry sample was loaded into a settling cup, placed into a plastic bag (to minimize evaporative losses), secured to a jack stand, and allowed to settle undisturbed for 4 days prior to using a vane to measure the settled solids yield stress. A 4-blade vane (diameter $=1.6 \mathrm{~cm}$, height $=1.6 \mathrm{~cm})$ was used. The vane was installed onto the M5 measuring head. The plastic bag was opened and the sample raised (using the jack) to the point where the top of the vane was flush with the top of the settled solids. The vane was then rotated through the sample at approximately 0.3 RPM for 3 minutes. Figure A2 shows the results and the response is typical of a material with yield stress. The maximum yield stress, or shear strength, was 5.2 Pa.

The sample in the measuring cup was then homogenized by hand using the vane. There were no issues, such as clumps or excess force required to mix this sample. Residual neptunium slurry material on the vane was flushed into a wide mouth bottle. An MV1 rotor was installed onto the M5 measuring head. The homogenized sample was then placed into a MV measuring cup and the cup installed onto the M5 measuring head. Excessive sample was removed.

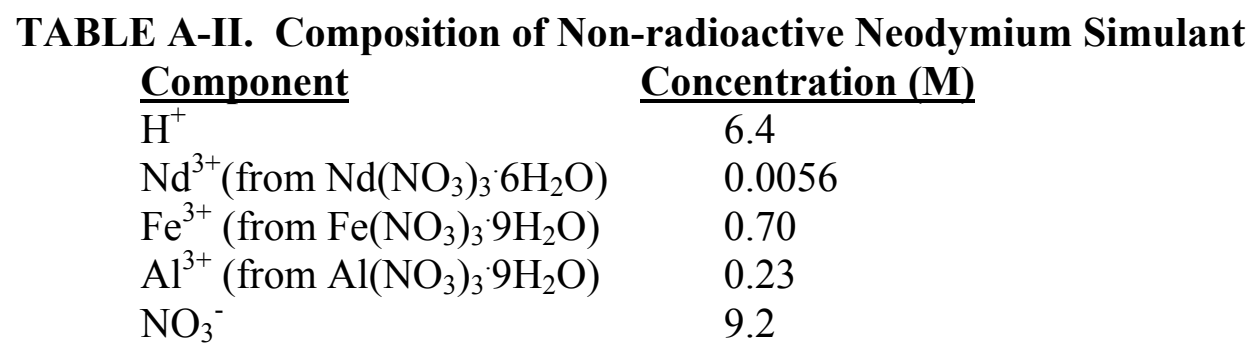




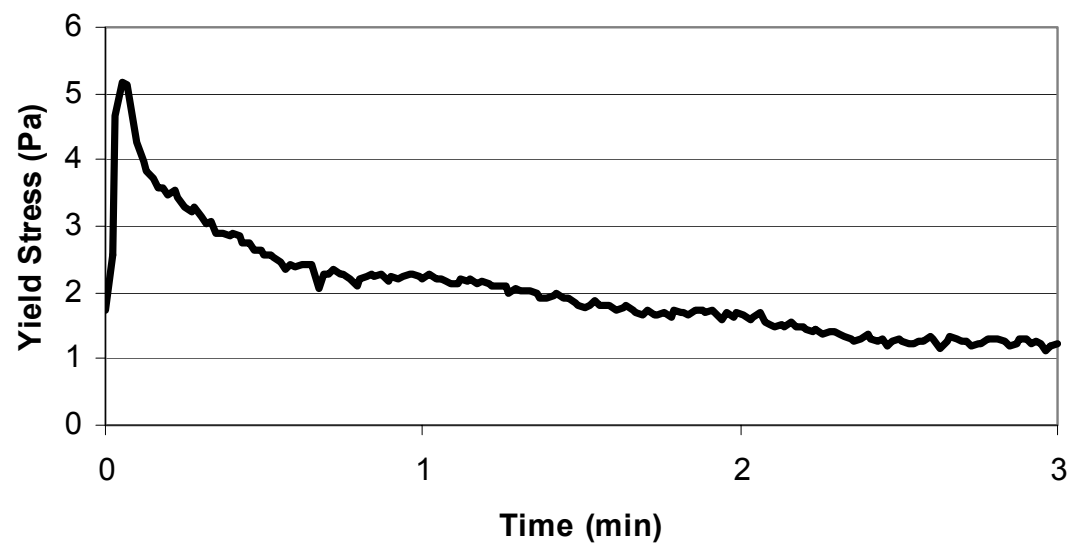

FIGURE A-2. Neptunium Slurry Yield Strength Measurement

A flow curve program (ramp from 0 to $1000 \mathrm{sec}^{-1}$ in 5 minutes, hold at $1000 \mathrm{sec}^{-1}$ for 1 minute, and ramp from 1000 to $0 \mathrm{sec}^{-1}$ in 5 minutes) was used and all measurements were performed at $25^{\circ} \mathrm{C}$. After the first flow curve measurement, the MV1 cup was removed and sample was added to the cup. The contents in the MV1 cup were mixed and the cup was then re-installed back onto the M5 measuring head and excess sample removed. The sample flow curve program was used. Table A-III shows the flow curve data.

The sample is somewhat non-Newtonian. Plotting of the Newtonian and Bingham Plastic results against the actual data show that any of the above results can be used. The flow curve data shows that the yield stress is very low $(<1 \mathrm{~Pa})$ after the material is mixed or sheared.

\section{TABLE A-III. Rheology Flow Curve Data}

\begin{tabular}{|c|c|c|c|c|c|c|}
\hline Newtonian & \multicolumn{2}{|c|}{ Viscosity (cp) } & \multicolumn{2}{|c|}{$\underline{\mathbf{R}^{2}}$} & & \\
\hline & Up & Down & Up & Down & & \\
\hline Run 1 & 7.86 & 7.38 & 0.9736 & 0.9964 & & \\
\hline Run 2 & 7.88 & 7.50 & 0.9851 & 0.9969 & & \\
\hline Average & 7.87 & 7.44 & & & & \\
\hline Average (up/down) & \multicolumn{2}{|c|}{7.65} & & & & \\
\hline Bingham Plastic & \multicolumn{2}{|c|}{ Consistency (cp) } & \multicolumn{2}{|c|}{ Yield Stress (Pa) } & \multicolumn{2}{|c|}{$\underline{\mathbf{R}}^{2}$} \\
\hline Run 1 & 6.92 & 7.05 & 0.63 & 0.22 & 0.9984 & 0.9993 \\
\hline Run 2 & 7.16 & 7.20 & 0.48 & 0.20 & 0.9985 & 0.9991 \\
\hline Average & 7.04 & 7.13 & 0.55 & 0.21 & & \\
\hline
\end{tabular}




\section{Rheometer Test on Neptunium Slurry Mixed with Washed Radioactive Sludge}

Approximately $60 \mathrm{~mL}$ of mixed slurry were removed from the "combined" SB2 Rheology sample bottle and placed into a calibrated $125 \mathrm{~mL}$ bottle to complete the first rheology measurement (sludge-only). To complete the second measurement, another 30 $\mathrm{mL}$ of mixed SB2 slurry (from the "combined" SB2 Rheology sample bottle) was added to the calibrated $125 \mathrm{~mL}$ bottle along with $\sim 3 \mathrm{~mL}$ of neptunium slurry ( $93 \mathrm{~mL}$ - total volume of $125 \mathrm{~mL}$ bottle after all additions). To complete the third rheology measurement, $\sim 3 \mathrm{~mL}$ of $0.01 \mathrm{M} \mathrm{NaOH}$ solution was added to the calibrated bottle containing the $90 \mathrm{~mL}$ of sludge slurry and Np Slurry. All of the rheological measurements for the sludge slurry samples were obtained using a Haake RV30/M5 system located in a shielded facility. A NIST traceable Newtonian oil standard ( $28 \mathrm{cP}$ (a) $25^{\circ} \mathrm{C}$ ) was used to check and verify the instrument's response prior to the start of the sludge slurry measurements and after the last sludge slurry measurement. The MVI rotor and MV cup was used in all of the measurements obtained. A flow curve program (ramp from 0 to $1100 \mathrm{sec}^{-1}$ in 5 minutes, hold at $1100 \mathrm{sec}^{-1}$ for 1 minute, and ramp from 1100 to $0 \mathrm{sec}^{-1}$ in 5 minutes) was used and all measurements were performed at $25^{\circ} \mathrm{C}$.

The data were curve fitted using the Bingham Plastic model between a shear rate of $86 \mathrm{~s}^{-1}$ to $1100 \mathrm{~s}^{-1}$. The Bingham plastic model is defined as follows.

$$
\begin{aligned}
& \mathrm{Tau}=\mathrm{Tau}_{\mathrm{o}}+\eta \mathrm{D} \text { or }\left\{\tau=\tau_{\mathrm{o}}+\eta / 100 \gamma\right\} \\
& \text { Where: } \quad \text { Tau }(\tau)=\text { Shear stress }\left\{\text { Dynes } / \mathrm{cm}^{2}\right\} \\
& \operatorname{Tau}_{\mathrm{o}}\left(\tau_{\mathrm{o}}\right)=\text { Shear stress at } \mathrm{D}=0 \mathrm{~s}^{-1}\left\{\text { Dynes } / \mathrm{cm}^{2}\right\} \text { or Yield Stress } \\
& \eta=\text { Consistency }\{\text { centipoise }=\mathrm{cP} \text { \} } \\
& \mathrm{D}(\dot{\gamma})=\text { shear rate }\left\{\mathrm{s}^{-1}\right\}
\end{aligned}
$$

\begin{tabular}{|c|c|c|c|c|}
\hline Slurry & $\begin{array}{c}\text { Fitted Shear } \\
\text { Rate Range }\left(s^{-1}\right)\end{array}$ & $\begin{array}{c}\underline{\tau}_{0} \\
(\text { Dynes/cm } \\
\left.\mathbf{c}^{2}\right)\end{array}$ & $\underset{(\mathbf{n})}{(\mathbf{c p})}$ & $\underline{\mathbf{R}}^{2}$ \\
\hline Washed sludge & $86-1100$ & 77.9 & 6.0 & 0.97 \\
\hline $\begin{array}{l}\text { Washed sludge } \\
+ \text { Neptunium }\end{array}$ & $86-1100$ & 73.7 & 6.0 & 0.98 \\
\hline $\begin{array}{l}\text { Washed sludge } \\
+ \text { Neptunium }+ \\
\text { inhibited water }\end{array}$ & $86-1100$ & 65.3 & 5.5 & 0.97 \\
\hline
\end{tabular}

Table A-IV lists the results of the curve fitting.

TABLE A-IV. Results of Bingham Plastic Model Curve Fit to Slurry Samples 


\section{APPENDIX B \\ Mixing and Transfer Modeling Calculations}

\section{Cavern Model Calculations}

Equations [1] - [3] describe the cavern model. ${ }^{7,8,9}$

$$
\begin{aligned}
& N_{c}=\frac{\pi}{D_{I}} \sqrt{\frac{\left(\frac{H_{c}}{D_{c}}+\frac{1}{3}\right)\left(\frac{T}{D_{I}}\right)^{3} \tau_{y}}{\rho N_{p}}} \\
& N_{c}=\sqrt{\frac{4 V_{c} \pi\left(\frac{H_{c}}{D_{c}}+\frac{1}{3}\right) \tau_{y}}{\left(\frac{H_{c}}{D_{c}}\right) \rho N_{p} D_{I}^{5}}} \\
& N_{c}=\sqrt{\frac{\left(\frac{T}{D_{I}}\right)^{3} \pi^{2} \tau_{y}}{1.32 N_{p} D_{I}^{2}}}
\end{aligned}
$$

In equations [B1] - [B-3], $N_{c}$ is the impeller speed required to mix the entire tank, $V_{c}$ is the cavern volume, $\mathrm{H}_{\mathrm{c}}$ is the cavern height, $\mathrm{D}_{\mathrm{c}}$ is the cavern diameter, $\mathrm{T}$ is the tank diameter, $D_{\mathrm{I}}$ is the impeller diameter, $\tau_{\mathrm{y}}$ is the slurry yield stress, $\rho$ is the slurry density, and $\mathrm{N}_{\mathrm{p}}$ is the impeller power number (assumed to be 3). For a well mixed tank, the cavern volume is equal to the slurry volume, the cavern height is equal to the slurry height in the tank and the cavern diameter is equal to the tank diameter.

Table B-I shows the operating parameters for the neutralization tank, along with the predictions for required agitator speed to mix the tank. The model predicts an agitator speed of $58 \mathrm{rpm}$ is needed to mix the slurry in the plant.

\section{Particle Settling Velocities}

The particle settling velocities for different sized particles were calculated by the following equations. ${ }^{22}$

$$
\begin{aligned}
& \mathrm{v}_{\mathrm{s}}=\mathrm{g}(\mathrm{s}-1) \mathrm{d}_{\mathrm{p}}^{2} / 18 \mathrm{v} \\
& \mathrm{v}_{\mathrm{s}}=0.13[\mathrm{~g}(\mathrm{~s}-1)]^{0.72} \mathrm{~d}_{\mathrm{p}}^{1.18} \mathrm{v}^{-0.45} \\
& \mathrm{v}_{\mathrm{s}}=1.74\left[\mathrm{~g}(\mathrm{~s}-1) \mathrm{d}_{\mathrm{p}}\right]^{0.5} \\
& \mathrm{Re}_{\mathrm{p}}=\mathrm{d}_{\mathrm{p}} \mathrm{v}_{\mathrm{s}} / \mathrm{v}
\end{aligned}
$$

for $\operatorname{Re}_{\mathrm{p}}<1.4$

for $1.4<\mathrm{Re}_{\mathrm{p}}<500$

for $\operatorname{Re}_{\mathrm{p}}>500$ 
TABLE B-1. Required Agitator Speed to Mix Settled Neptunium Slurry

$\frac{\text { Parameter }}{\mathrm{H}_{\mathrm{c}}}$
$\mathrm{D}_{\mathrm{c}}$
$\mathrm{T}$
$\mathrm{D}_{\mathrm{I}}$
$\tau_{\mathrm{y}}$
$\rho$
$\mathrm{N}_{\mathrm{p}}$
$\mathrm{N}_{\mathrm{c}}$ (Equation [1])
$\mathrm{N}_{\mathrm{c}}$ (Equation [2])
$\mathrm{N}_{\mathrm{c}}$ (Equation [3])
Average

Tip speed

$\begin{array}{lll}\frac{\text { Plant-Scale Tank }}{3.8 \mathrm{ft}} & & \text { Lab-Scale } \\ 6.0 \mathrm{ft} & & 3.64 \mathrm{~cm} \\ 6.0 \mathrm{ft} & 3.95 \mathrm{~cm} \\ 2.0 \mathrm{ft} & 1.9 \mathrm{~cm} \\ 52 \mathrm{dynes} / \mathrm{cm}^{2} & & 52 \mathrm{dynes} / \mathrm{cm}^{2} \\ 1.322 \mathrm{~g} / \mathrm{ml} & & 1.322 \mathrm{~g} / \mathrm{mL} \\ 3 & 3 \\ 57 \mathrm{rpm} & 1077 \mathrm{rpm} \\ 57 \mathrm{rpm} & 1077 \mathrm{rpm} \\ 58 \mathrm{rpm} & 1077 \mathrm{rpm} \\ 58 \mathrm{rpm} & 1077 \mathrm{rpm} \\ 6.0 \mathrm{ft} / \mathrm{sec} & 3.5 \mathrm{ft} / \mathrm{sec}\end{array}$

where $\mathrm{v}_{\mathrm{s}}$ is the settling velocity, $\mathrm{g}$ is the acceleration due to gravity, $\mathrm{s}$ is the ratio of particle and fluid densities ( $\mathrm{s}=$ particle density/fluid density), $\mathrm{d}_{\mathrm{p}}$ is the particle diameter, and $v$ is the fluid kinematic viscosity $(v=\mu / \rho)$.

To perform the calculation, one assumes a particle Reynolds number, calculates the settling velocity with the appropriate equation, and calculates a new particle the Reynolds number with the calculated settling velocity. If the Reynolds number is in the correct range for the equation used, the calculated settling velocity is correct. If the Reynolds number is not in the correct range for the equation used, use a different equation to calculate the settling velocity. Repeat these steps as necessary.

\section{Fast-Settling Particle Suspension Correlations}

Table B-II shows the correlations developed for fast-settling particle suspension. In Table B-II, $\rho_{\mathrm{s}}$ is the particle density, $\rho_{\mathrm{f}}$ is the fluid density, $\mathrm{g}$ is the gravitational constant, $\mathrm{d}_{\mathrm{p}}$ is the particle size, $C_{v}$ is particle volume concentration, $T$ is tank diameter, $C_{D}$ is the drag coefficient, Po is the power number, $\mathrm{D}$ is the impeller diameter, $\mathrm{Z}$ is the liquid height, $v$ is the kinematic viscosity, $\mu$ is the fluid viscosity, $X$ is the particle weight fraction, and $\mathrm{S}$ is a constant. Typical values of $\mathrm{S}$ are between 5 and 7. 
TABLE B-II Agitator Speed Required to Suspend Insoluble Particles

Reference

Shamlou $^{11}$

Baldi et. al $^{12}$

Zwietering $^{13}$

Chapman et. $\mathrm{al}^{14}$

\section{Correlation}

$$
N_{j s}=\frac{3.5\left(\frac{\rho_{s}-\rho_{f}}{\rho_{f}}\right)^{1 / 2} g^{1 / 2} d_{p}{ }^{1 / 6} C_{v}{ }^{1 / 3} T}{C_{D}{ }^{1 / 6} P o^{1 / 3} D^{5 / 3}} \propto \frac{d_{p}{ }^{1 / 6} C_{v}{ }^{1 / 3} T}{D^{5 / 3}}
$$

$$
N_{j s}=\left(\frac{g\left(\rho_{s}-\rho_{f}\right)}{\rho_{f}}\right)^{1 / 2} \frac{1}{P o^{1 / 3}}\left(\frac{T}{D}\right) \frac{d_{p}{ }^{1 / 6}}{D^{2 / 3}} \frac{1}{Z} \propto \frac{d_{p}{ }^{1 / 6} T}{D^{5 / 3} Z}
$$

$$
N_{j s}=\frac{S v^{.1} d_{p}{ }^{2}\left(\frac{g\left(\rho_{s}-\rho_{f}\right)}{\rho_{f}}\right)^{.45} X^{.13}}{D^{.85}} \propto \frac{d_{p}{ }^{2} X^{.13}}{D^{.85}}
$$

$$
N_{j s}=\frac{S v^{.1} d_{p}{ }^{.15}\left(\frac{g\left(\rho_{s}-\rho_{f}\right)}{\rho_{f}}\right)^{.4} X^{.12}}{D^{.76}} \propto \frac{d_{p}{ }^{.15} X^{.12}}{D^{.76}}
$$

The following parameter values were used in the calculations.

- The particle density is $2.0-5.24 \mathrm{~g} / \mathrm{cc}$.

- The fluid density is $1.322 \mathrm{~g} / \mathrm{cc}$.

- The fluid viscosity is $7.65 \mathrm{cp}$.

- The particle size is $18 \mu, 31 \mu, 62 \mu$., and $88 \mu$.

- Tank diameter is $1.83 \mathrm{~m}$.

- Impeller diameter is $0.61 \mathrm{~m}$.

- Impeller power number is 3 .

- Insoluble solid particle concentration is 5\%.

- Liquid density is $1.322 \mathrm{~g} / \mathrm{ml}$.

- $\mathrm{S}$ is 6 .

- Kinematic viscosity is $0.059 \mathrm{~cm} 2 / \mathrm{s}$.

- Drag coefficient is 2 .

- $\mathrm{Z}$ is 1 . 


\section{APPENDIX C Hydrogen Generation Calculations}

The hydrogen generation calculations followed the assessment made for the americium/curium addition to Sludge Batch $3 .^{24}$ The following equation predicts the rate of hydrogen gas generation $\left(\mathrm{R}_{i}, \mathrm{lbs} / \mathrm{hr}\right)$ for each radionuclide (i).

$$
\begin{aligned}
\mathrm{R} i=\mathrm{Q}_{i} \mathrm{~W}_{i} & \left.-\underline{\mathrm{G}_{i}} \underline{100} \underset{\text { mole H}_{2}}{\left[2.0 \mathrm{~g} \mathrm{H}_{2}\right.}\right]\left[\frac{1 \text { mole }}{6.022 \mathrm{E} 23 \text { molecules }}\right][3600 \mathrm{sec} / \mathrm{h}]\left[\frac{1 \mathrm{eV} / \mathrm{sec}}{1.602 \mathrm{E}-19 \text { watts }}\right]\left[\frac{1 \mathrm{lb}}{453.6 \mathrm{~g}}\right] \\
\text { where } \mathrm{Q}_{i} & =\text { number of curies of radionuclide } \mathrm{i}(\mathrm{Curies}) \\
\mathrm{W}_{\mathrm{i}} & =\text { decay heat (watts } / \mathrm{Ci} \text { ) } \\
\mathrm{G}_{\mathrm{i}} & =\text { radiolytic yield (molecules } / 100 \mathrm{eV}) .
\end{aligned}
$$

For the purposes of this calculation, each radionuclide is assigned a bounding $\mathrm{G}$ value based on the type of decay it undergoes, either beta/gamma or alpha decay. The $\mathrm{G}$ value for beta/gamma is 0.45 molecules $/ 100 \mathrm{eV}$ and for alpha is 1.6 molecules/ $100 \mathrm{eV}{ }^{24}$ The calculation assumes all of the decay energy is absorbed by water in the waste.

Table I of this report lists the concentrations of the major radionuclides that contribute to hydrogen generation from the 8,300 gallons of neptunium solution (containing $34 \mathrm{~kg}$ of neptunium) currently stored in H-Canyon Tank 16.4. In addition to the current inventory, an additional $18 \mathrm{~kg} \mathrm{~Np}$ will transfer to Tank 16.4 by April $2004 .^{2}$ We assumed that the additional $18 \mathrm{~kg}$ will be accompanied by the same radionuclide distribution found in the current inventory. Thus, the final volume transferred volume will equal 12,700 gallons with the composition shown in Table I. The preliminary report from H-Canyon personnel list additional radionuclides concentrations used in the calculation. ${ }^{2}$ Table C-I shows the data used and the results of the calculation of the hydrogen generation rate for the neptunium solution.

SRTC researchers previously calculated hydrogen generation rates for Sludge Batches 2 and 3. ${ }^{24}$ The value reported for Sludge Batch $2\left(1.60 \times 10^{-3} \mathrm{lbs} / \mathrm{hr}\right)$ is corrected to reflect a smaller inventory of washed sludge at the time the neptunium transfer occurs. The corrected value assumes 359,000 gallons of washed sludge at a density of $1.12 \mathrm{~kg} / \mathrm{L}$ and containing $19 \mathrm{wt} \%$ sludge solids. This corresponds to $2.89 \times 10^{5} \mathrm{~kg}$ of dry oxides compared to the previously reported value of $4.37 \times 10^{5} \mathrm{~kg}$. The following calculation yields the hydrogen gas generation rate at the time of the neptunium transfer.

$$
1.60 \times 10^{-3} \frac{\mathrm{lbs}}{\mathrm{hr}} \times \frac{2.89 \times 10^{5} \mathrm{~kg}}{4.37 \times 10^{5} \mathrm{~kg}}=1.06 \times 10^{-3} \mathrm{lbs} / \mathrm{hr}
$$

The hydrogen generation rate reported for Sludge Batch 3 Case 4 (includes Am/Cm and $\mathrm{Pu}$ transfers $)$ is used without modification $\left(4.02 \times 10^{-2} \mathrm{lbs} / \mathrm{hr}\right)$. 
WSRC-TR-2003-00144, Rev. 0

Page 39 of 40

TABLE C-I. Hydrogen Generation Rate for Neptunium Solution

\section{Radionuclide}

C-14

Sr-90

Y-90

Cs-137

Ba-137m

Eu-154

$\mathrm{U}-234$

$\mathrm{U}-235$

$\mathrm{U}-236$

$\mathrm{U}-238$

Np-237

Pu-238

Pu-239

Pu-240

$\mathrm{Pu}-241$

Pu-242

Ingrown Am-241

Am-241

Am-242m

Am-2423

$\mathrm{Cm}-244$

Cm-245
Radiatio

Wi
(watts/Ci

2.93E-04

$1.16 \mathrm{E}-03$

5.44E-03

$1.01 \mathrm{E}-03$

3.94E-03

9.08E-03

2.83E-02

2.71E-02

2.66E-02

2.49E-02

2.88E-02

3.26E-02

3.02E-02

3.06E-02

3.20E-05

2.90E-02

3.28E-02

3.28E-02

4.05E-04

3.15E-02

3.44E-02

3.33E-02 n

type

Beta

Beta

Beta

Beta

Gamma

Gamma

Alpha

Alpha

Alpha

Alpha

Alpha

Alpha

Alpha

Alpha

Beta

Alpha

Alpha

Alpha

Alpha

Alpha

Alpha

Alpha

Gi
(molecules/100 eV)

0.45
0.45
0.45
0.45
0.45
0.45
1.6
1.6
1.6
1.6
1.6
1.6
1.6
1.6
0.45
1.6
1.6
1.6
1.6
1.6
1.6
1.6

Total (lbs/hr) $\begin{array}{cc} & \mathrm{Ri} \\ \mathrm{Qi} & (\mathrm{lbs} / \mathrm{hr})\end{array}$

(Curies) (Ibs/hr)

$0.00 \mathrm{E}+00 \quad 0.00 \mathrm{E}+00$

$0.00 \mathrm{E}+00 \quad 0.00 \mathrm{E}+00$

$0.00 \mathrm{E}+00 \quad 0.00 \mathrm{E}+00$

4.56E+01 3.41E-08

4.56E+01 1.33E-07

$0.00 \mathrm{E}+00 \quad 0.00 \mathrm{E}+00$

$1.01 \mathrm{E}+00 \quad 7.52 \mathrm{E}-08$

$1.96 \mathrm{E}-03 \quad 1.40 \mathrm{E}-10$

1.82E-02 1.27E-09

2.57E-04 1.68E-11

4.47E+01 3.39E-06

9.52E+02 8.17E-05

$3.75 \mathrm{E}+00 \quad 2.98 \mathrm{E}-07$

$5.17 \mathrm{E}+00 \quad 4.16 \mathrm{E}-07$

3.57E+02 8.46E-09

4.44E-02 3.39E-09

$0.00 \mathrm{E}+00 \quad 0.00 \mathrm{E}+00$

$5.48 \mathrm{E}+00 \quad 4.73 \mathrm{E}-07$

$0.00 \mathrm{E}+00 \quad 0.00 \mathrm{E}+00$

$0.00 \mathrm{E}+00 \quad 0.00 \mathrm{E}+00$

$0.00 \mathrm{E}+00 \quad 0.00 \mathrm{E}+00$

$0.00 E+00 \quad 0.00 E+00$

Note: The generation rate is based on 12,7000 gallons of neptunium solution ( $52 \mathrm{~kg} \mathrm{~Np}$ ).

The following calculations show the percentage change caused by adding the neptunium solution to the sludge batches.

SB2: $\quad 100\left(8.65 \times 10^{-5} \mathrm{lbs} / \mathrm{hr}\right) /\left(1.06 \times 10^{-3} \mathrm{lbs} / \mathrm{hr}\right)=8.2 \%$ increase

SB3: $100\left(8.65 \times 10^{-5} \mathrm{lbs} / \mathrm{hr}\right) /\left(4.02 \times 10^{-2} \mathrm{lbs} / \mathrm{hr}\right)=0.21 \%$ increase 


\section{REFERENCES}

${ }^{1}$ S. H. Reboul and H. H. Elder, "Preliminary Engineering Assessment of Potential Neptunium Disposition Options into HLW and Path Forward," HLW-PRE-2002-0051, Rev. 0, December 10, 2002.

2 W. G. Dyer, "H-Canyon Neptunium Disposition Options and Variations," CBU-HCP-2003-00003, February 20, 2003.

${ }^{3}$ D. G. Karraker, "Solubility of Neptunium in Alkaline High Level Waste," WSRC-TR-94-0526, Rev. 1, 1994.

${ }^{4}$ D. P. Lambert, T. B. Peters, M. E. Stallings, M. R. Poirier, and S. D. Fink, "Determining the Cause for Low Flowrates During Am/Cm Simulant Testing in F Area," WSRC-TR-2002-00569, Rev. 0, April 14, 2003.

${ }^{5}$ T. L. Fellinger, "Status Report Summarizing the shielded Cells Phase I Rheological Work for Sludge Batch 2 (U)," WSRC-TR-2003-00136, April 4, 2003.

6 "Technical Data Summary for the Defense Waste Processing Facility: Sludge Plant," DPSTD-80-38-2.

${ }^{7}$ T. P. Ellson, D. J. Cheesman, and A. W. Nienow, "X-Ray Studies of Cavern Sizes and Mixing Performance with Fluids Possessing a Yield Stress," Chem. Eng. Sci, 41(10), 2555-2562 (1986).

${ }^{8}$ T. P. Ellson, "The Growth of Caverns Formed Around Rotating Impellers During the Mixing of a Yield Stress Fluid," Chem. Eng. Comm.,96, 303-319(1990).

${ }^{9}$ A. W. Etchells, W. N. Ford, and D. G. R. Short, "Mixing of Bingham Plastics on an Industrial Scale", Fluid Mixing III: The Institution of Chemical Engineers Symposium Series, No. 108, pp. 271-285, 1987.

${ }^{10}$ V. W. Uhl and J. B. Gray, Mixing: Theory and Practice, Vol. 3, Academic Press, Orlando, 1986.

${ }^{11}$ P. Ayazi Shamlou, "Suspension of Particles in Liquids in Stirred Vessels", in P. Ayazi Shamlou, Ed., Processing of Solid-Liquid Suspensions, Butterworth-Heinemann, Boston, 1993.

${ }^{12}$ G. Baldi, R. Conti, and E. Alaria, Chem. Eng. Sci., 33, 21 (1978).

13 T. N. Zwietering, Chem. Eng. Sci., 8, 244 (1958)

${ }^{14}$ C. M. Chapman, A. W. Nienow, and J. C. Middleton, Trans. I. Chem. E., 59, 134 (1981).

${ }^{15}$ D. M. Newitt, J. F. Richardson, M. Abbott, and R. B. Turtle, "Hydraulic Conveying of Solids in Horizontal Pipes," Trans. Instn. Chem. Engrs., 33, 93-110 (1955).

${ }^{16}$ W. Parzonka, J. M. Kenchington, and M. E. Charles, "Hydrotransport of Solids in Horizontal Pipes: Effects of Solids Concentration and Particle Size on the Deposit Velocity," Can. J. Chem. Eng., 59, 291296 (1981).

${ }^{17}$ T. C. Aude, N. T. Cowper, T. L. Thompson, and E. J. Wasp, "Slurry Piping Systems: Trends, Design Methods, Guidelines," Chem. Engr., June 28, 1971, pp 74-90.

${ }^{18}$ R. M. Turian and T.-F. Yuan, "Flow of Slurries in Pipelines," AIChE Journal, 23, 232-243 (1977).

${ }^{19}$ A. W. Etchells, "Slurry Handling Problems in te Process Industries," in P. Ayaza Shamlou, Ed., Processing of Solid-Liquid Suspensions, Butterworth-Heinemann, Boston, 1993.

${ }^{20}$ N. I. Heywood, "Stop Your Slurries from Stirring Up Trouble," Chem. Eng. Prog., 95(9), 21-41 (1999).

${ }^{21}$ C. A. Shook, "Slurry Pipeline Flow," in P. Ayazi Shamlou, Ed., Processing of Solid-Liquid Suspensions, Butterworth-Heinemann, Boston, 1993.

${ }^{22}$ I. C. Walton, "Eddy Diffusivity of Solid Particles in a Turbulent Liquid Flow in a Horizontal Pipe," AIChE Journal, 41, 1815-1820 (1995).

${ }^{23}$ R. M. Turian, F.-L.Hsu, and T.-W. Ma, "Estimation of the Critical Velocity in Pipeline Flow of Slurries," Powder Technology, 51, 35-37 (1987).

${ }^{24}$ D. K. Peeler, N. E. Bibler, and T. B. Edwards, "An Assessment of the Impacts of Adding Am/Cm and $\mathrm{Pu} / \mathrm{Gd}$ Waste Streams to Sludge Batch 3 (SB3) on DWPF $\mathrm{H}_{2}$ Generation Rates and Glass Properties (U)," WSRC-TR-2002-00145, Rev. 0, 2002. 